\title{
Mapping of Retinal and Geniculate Neurons onto Striate Cortex of Macaque
}

\author{
Stanley J. Schein ${ }^{1}$ and Francisco M. de Monasterio ${ }^{2}$ \\ ${ }^{1}$ Howe Laboratory, Harvard Medical School, Massachusetts Eye and Ear Infirmary, Boston, Massachusetts 02114, and \\ 2National Eye Institute, $\mathrm{NIH}$, Bethesda, Maryland 20892
}

\begin{abstract}
A unity ratio between geniculate and ganglion cells can be shown in the macaque visual system. Comparison of the densities (cells/ $\mathrm{deg}^{2}$ ) in the dorsal lateral geniculate nucleus (dLGN) of parvocellular (P) and magnocellular (M) cells, respectively, representing color-opponent and broad-band ganglion cells, with cortical magnification $\left(\mathrm{mm}^{2} / \mathrm{deg}^{2}\right)$ gives the number of afferents per square millimeter in striate cortex (V1). For $P$ cells, this afferent density rises only slightly with eccentricity, indicating that V1 magnification is approximately proportional to the density of $P$ cells. The density of cytochrome oxidase puffs in V1 also rises only slightly with eccentricity. As a result, the number of P-cell afferents per puff-centered module is remarkably constant throughout $V 1$. Our findings thus support a novel hypothesis of peripheral scaling, in which $\mathbf{V} 1$ cortical magnification is based on the mapping of just 1 class of afferent onto V1 modules. This "P-cell module" in V1 may be composed of submodules corresponding anatomically to the honeycomb cell in layer $4 \mathrm{~A}$ of $\mathrm{V} 1$ and physiologically to a minimal complete set of color-opponent ganglion cells.

In contrast, the afferent density of $M$ cells rises steeply with eccentricity, so that the reciprocal of their afferent density, the cortical "domain" of $M$ cells, declines with eccentricity. This decline is similar to that of point-image area in $V 1$. As a result, the number of $M$ cells per point-image area is nearly constant. This quantity is analogous to the receptive-field coverage factor in the retina, which for $M$ cells is fairly constant and greater than unity at all eccentricities. The results show fundamental differences between the neural maps of these 2 major cell types, differences that are likely to have psychophysical consequences.
\end{abstract}

The retina encodes the visual scene into a neural representation that is successively transformed at the various levels of the visual system. The representation at each level may be composed of superimposed maps mediated by functionally distinct neuronal classes. The retinal output to the dorsal lateral geniculate nucleus (dLGN) of the macaque is conveyed primarily by 2 major classes of ganglion cell. One class consists of neurons with small receptive fields, slow conduction velocity, and color-opponent responses. The other class consists of neurons with larger re-

Received Feb. 3, 1986; revised Oct. 28, 1986; accepted Oct. 28, 1986.

S.J.S. received partial support from Research to Prevent Blindness, Inc., the Massachusetts Lions Eye Research Fund, and NIH Grant 1 R01 EY06096-01.

Correspondence should be addressed to Stan Schein, Massachusetts Eye and Ear Infirmary, 243 Charles Street, Boston, MA 02114.

Copyright (C) 1987 Society for Neuroscience $0270-6474 / 87 / 040996-14 \$ 02.00 / 0$ ceptive fields, faster conduction velocity, and broad-band responses (Gouras, 1969; de Monasterio and Gouras, 1975; Schiller and Malpeli, 1977; de Monasterio, 1978a-c). In the dLGN these 2 cell classes seem to segregate into the parvocellular $(P)$ and magnocellular (M) layers (Wiesel and Hubel, 1966; Bunt et al., 1975; Dreher et al., 1976; Marrocco, 1976; Leventhal et al., 1981; Shapley et al., 1981; Kaplan and Shapley, 1982; Marrocco et al., 1982; Schiller and Colby, 1983; Derrington and Lennie, 1984; Derrington et al., 1984; Perry et al., 1984; Rodieck et al., 1985).

This duality of the retinogeniculate pathway led us to examine the possibility that there might be differences in the nature of the mapping onto striate cortex of the 2 classes of afferent cells, which for brevity we shall refer to as P and M dLGN cells and P-like and M-like ganglion cells. From the results of different studies on macaque we have found that the eccentricity dependence of the density (cells/deg ${ }^{2}$ of dLGN cells is a good descriptor of that of ganglion cells, so that it can be used as a measure of neural magnification in both the retina and dLGN. We have, then, compared the $\mathrm{P}$ and $\mathrm{M}$ dLGN-cell densities with the areal cortical magnification factor $\left(\mathrm{mm}^{2} / \mathrm{deg}^{2}\right)$ of striate cortex, or area V1, to examine the degree of uniformity of the separate mappings of these 2 retinogeniculate cell types.

We describe 2 major results. First, the number of P-cell afferents per unit area of V1 seems to be nearly constant with eccentricity. Actually, if it is assumed that anatomical modules are centered on the cytochrome oxidase puffs (Horton and Hubel, 1980; Humphrey and Hendrickson, 1980), then throughout the visual field the area of such a module would receive a constant number of $P$-cell afferents. Subdivision of this "P-cell module" in V1 may be indicated in layer 4A, each submodule corresponding to what might be a minimal complete set of coloropponent ganglion cells.

Second, in contrast to the uniform mapping of P-cell afferent onto V1, the number of M-cell afferents per unit area of V1 increases very steeply with eccentricity. In this case it is the V1 point image, that is, "the locus of all cells whose receptive fields contain a given point in the visual field" (McIlwain, 1976), that would receive a constant number of M-cell afferents. The coverage factor in the retina is analogous to the point image. Computed as the product of cell-density and receptive-field areas, cell-density $\mathrm{M}$-cell receptive-field coverage is fairly constant and greater than unity at all eccentricities.

The variation of M-cell receptive-ficld area with eccentricity is also different from that of reciprocal cortical magnification. These findings suggest major differences in the nature and function of the cortical mappings subserved by these 2 retinal/geniculate classes. 

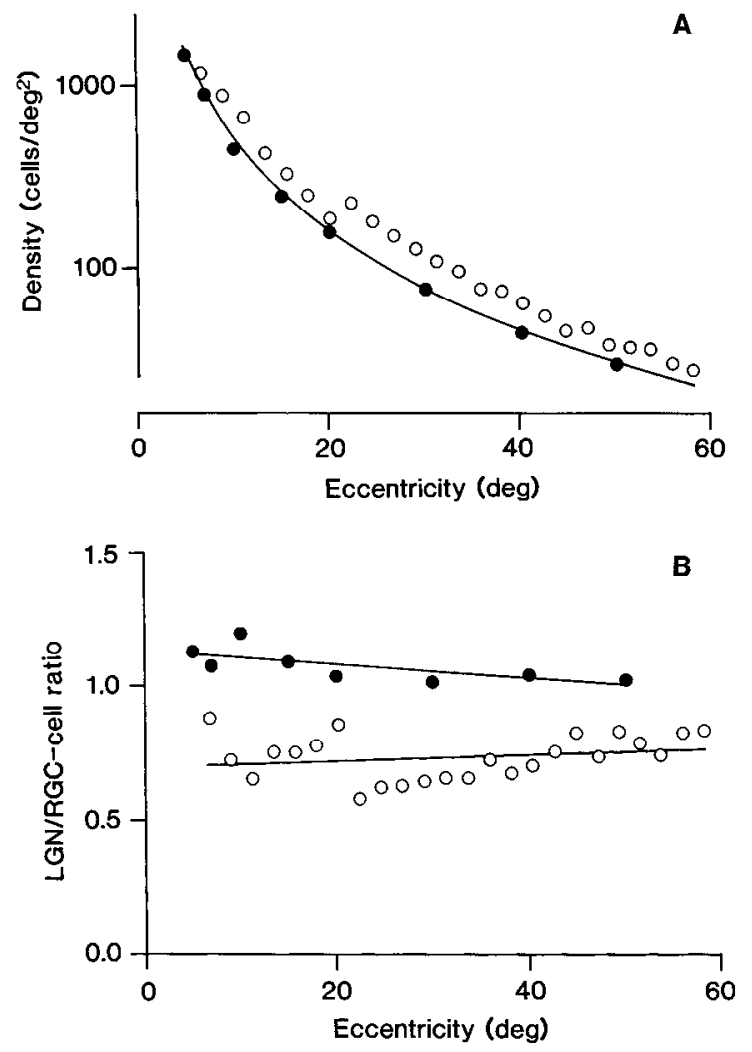

Figure 1. $A$, Density of retinal ganglion cells (RGC) and dorsal lateral geniculate cells (LGN) in macaque. Filled circles are retinal data from Rolls and Cowey (1970), based on their use of a $246 \mu \mathrm{m} / \mathrm{deg}$ conversion factor. Open circles arc rctinal data from Pcrry et al. (1984), based on the $223 \mu \mathrm{m} / \mathrm{deg}$ conversion factor of Perry and Cowey (1985). Both sets of data were corrected for shrinkage by the respective authors. For the filled circles, data from the nasal, temporal, dorsal, and ventral meridia were averaged and converted to cells $/ \mathrm{deg}^{2}$. The solid curve shows the density of LGN cells corresponding to 1 eye, or $1 / 2 \times$ equation (1), an equation derived from Connolly and Van Essen (1984) (see Materials and Methods). $B$, Ratio of LGN to RGC cells. The 2 sets of ratios correspond to the data in $A$. The regression line for ratios based on the first set of RGC data is $1.075-0.0026 \times$ Eccentricity; the regression line for the ratios based on the second set is $0.694+0.0011 \times$ Eccentricity.

A brief presentation of these results was given at the 1985 meeting of the Association for Research in Vision and Ophthalmology (Schein and de Monasterio, 1985).

\section{Materials and Methods}

The several sources of data that have been used in the calculations described in the present study are listed below. Unless otherwise stated, densities are expressed in terms of cells/ $\mathrm{deg}^{2}$.

Ganglion-cell densities. To assist in the comparison of ganglion-cell to neuronal densities in the dLGN, Figure $1 A$ shows 2 available sets of ganglion-cell data after their multiplication by 0.9 , since $10 \%$ of the ganglion cells in the ganglion-cell layer do not project to the dLGN (Perry et al., 1984). Solid circles show data from Rolls and Cowey (Fig. 9,1970 ) for the horizontal meridian of 5 macaque retinas measured from serial radial sections and corrected for the number of split cells in the cut faces. Open circles show the mean of data from Perry et al. (Fig. $8,1984)$ for the nasal, temporal, dorsal, and ventral meridia.

Rolls and Cowey (1970) noted that the marked central thickening of the ganglion-cell layer created uncertainties in their data at eccentricities of less than $5^{\circ}$. These uncertainties would be expected in all density measurements in the centralmost retina, including the foveal counts obtained by Perry et al. (1984) from flat mounts. Perry et al. (1984) noted agreement with the ganglion-cell densities reported by Rolls and Cowey (1970) for the central retina but significant disagreement for the

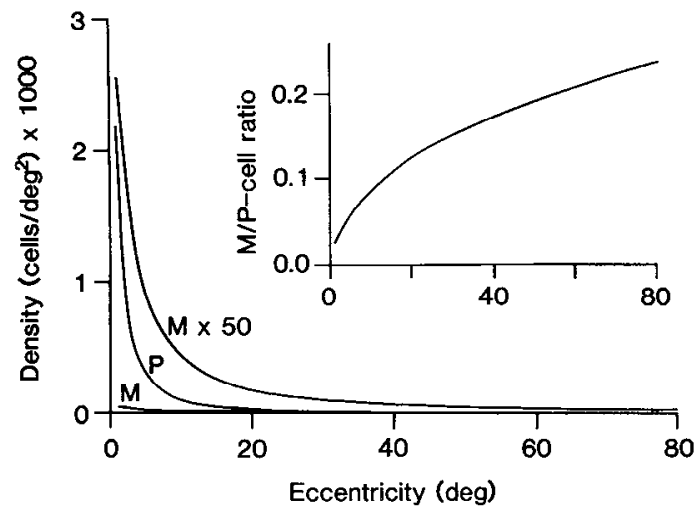

Figure 2. Parvocellular $(P)$ and magnocellular $(M)$ cell densities, along with the curve of $M \times 50$, in the dorsal lateral geniculate nucleus of the macaque. $P$ and $M$ values are based on Connolly and Van Essen (1984) [equations (2) and (3), respectively]. Inset shows the ratio of M to $P$ cells.

nasal meridian in the periphery. Nevertheless, as shown in Figure $1 A$, when the data in each study are averaged across meridians, the agreement is good in the periphery as well.

Rolls and Cowey (1970) used a distance-to-angle conversion factor of $246 \mu \mathrm{m} / \mathrm{deg}$. De Monasterio et al. (1985) found considerable variation in this factor, with an average of $203 \mu \mathrm{m} / \mathrm{deg}$. The middle value of 223 $\mu \mathrm{m} / \mathrm{deg}$ reported by Perry and Cowey (1985) was applied to the data of Perry et al. (1984) to convert cell densities in cells $/ \mathrm{mm}^{2}$ to cells $/ \mathrm{deg}^{2}$ and eccentricities (mm) to eccentricities (deg). In the region of the fovea, the centrifugal displacement of ganglion cells invalidates this method of conversion (see Discussion). For this reason, and because of the uncertainties noted above, only data beyond $5^{\circ}$ are used in Figure $1 A$.

$d L G N$-cell densities. On the basis of the mapping by Malpeli and Baker (1975) of the representation of the visual field in the dLGN and measurements of dLGN-cell density (cells $/ \mathrm{mm}^{3}$ ) by Clark (1941), Connolly and Van Essen (1984) transformed P, M, and total cell counts into their respective densities and reported equations for each cell compartment (their Table 1). Integration of their equation for total cells in dLGN gives a number that is lower than their reported number by a factor of 1.31 , and integration of their $P$ and $M$ equations gives similarly low numbers. (See Integration of Magnification Equations, below, for details of integration.) To satisfy the reported values, we have incorporated this additional factor in their density equations, in which eccentricity $(\mathrm{Ecc})$ is expressed in degrees of visual field:

$$
\text { dLGN total cells }-108,000 \times(E c c+1.31)-1.90
$$

The comparison of dLGN with ganglion cells involves 1 eye's worth of dLGN cells, however, so the dLGN data of Figure $1 A$ (solid curve) were generated by multiplying equation (1) by $1 / 2$ :

$$
\begin{aligned}
\mathrm{dLGN} P \text { cells } & =110,000 \times(\mathrm{Ecc}+1.28)-1.96 \\
\mathrm{dLGN} M \text { cells } & =4600 \times(\mathrm{Ecc}+3.12)-1.56
\end{aligned}
$$

The densities of $P$ and $M$ cells in dLGN, given by equations (2) and (3), are plotted in Figure 2, where the uppermost curve represents M-cell density multiplied by 50 to permit a better comparison of the shape of the eccentricity dependence of the 2 cell types. The inset shows the $M /$ $\mathrm{P}$-cell ratio. Variations in cell density along different meridia (Van $\mathrm{Bu}$ ren, 1963; Perry et al., 1984) are necessarily averaged in these equations. As a result of correction by multiplication by 1.31 , these 3 equations give a total of $1.3 \times 10^{6} \mathrm{dLGN}$ cells, $1.13 \times 10^{6} \mathrm{P}$ cells, and $1.21 \times$ $10^{5} \mathrm{M}$ cells.

It is not possible to ascertain the uncertainty and natural variation of the dLGN-cell densities estimated by Connolly and Van Essen (1984). In addition, the visual-field map of dLGN by Malpeli and Baker (1975) did not extend into the centralmost region. Therefore, we have chosen to restrict our analysis to eccentricities larger than $1^{\circ}$.

If the visual field were fairly divided up into contiguous territories, 1 to a $P$ cell, each territory of the visual field could be called the "visualfield domain" of a P cell (de Monasterio et al., 1985; Shapiro et al., 1985). This domain can be calculated from the reciprocal of density and is therefore in units of $\mathrm{deg}^{2} /$ cell. The notion of domain, which is a mathematical abstraction, is independent of the receptive field of a cell. 


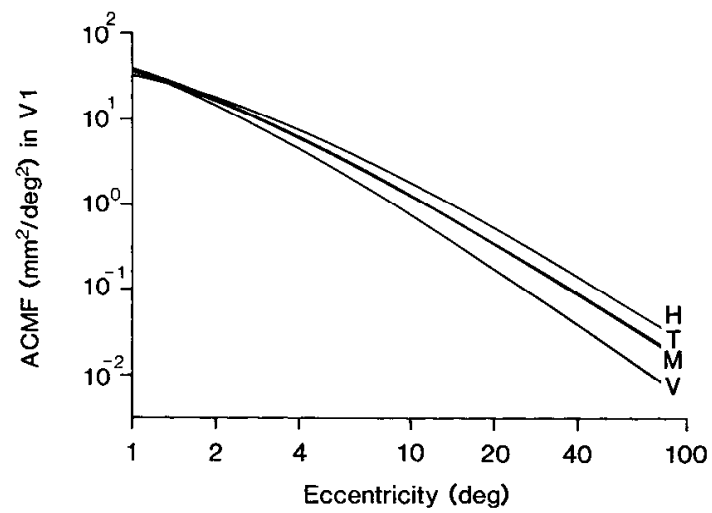

Figure 3. Areal cortical magnification factor $(A C M F)$ in macaque V1 from Hubel and Freeman (1977) [H, equation (4a)], Van Essen et al. (1984) [ $V$, equation (4b)], and Tootell et al. (1982) [ $T$, equation (4c)], as well as their mean $(M)$. $T$ and $M$ curves overlap extensively.

Areal cortical magnification factor. The linear cortical magnification factor is a magnitude describing, at a given eccentricity in the visual field, the distance along the cortical surface necessary to move $1^{\circ}$ in the representation of the visual field (Talbot and Marshall, 1941). Since areal cortical magnification factor (ACMF) (Myerson et al., 1977; Tusa et al., 1978) is more useful for our purposes, equations $(4 a-c)$ show the square of linear magnification, providing values in $\mathrm{mm}^{2} / \mathrm{deg}^{2}$. Equation (4a) is from Hubel and Freeman (1977), whose measurements extended to $22^{\circ}$ in striate cortex of macaques. Equation (4b), from Van Essen et al. (1984), is based on extensive mapping of the peripheral representation of a single macaque. Both studies reported cortical magnification in macaque $\mathrm{V} 1$ on the basis of electrophysiological recordings and anatomical reconstruction. Equation (4c) is from Tootell et al. (1982), who measured magnification from 2-deoxyglucose maps in the central $10^{\circ}$ :

$$
\begin{aligned}
& \mathrm{ACMF}=15.7^{2} \times(\mathrm{Ecc}+1.71)-2.0 \\
& \mathrm{ACMF}=11.8^{2} \times(\mathrm{Ecc}+0.78)-2.20 \\
& \mathrm{ACMF}=12.2^{2} \times(\mathrm{Ecc}+0.94)-2.0
\end{aligned}
$$

Figure 3 shows the double-log plot of the individual ACMr curves and their mean; curves $\mathrm{H}, \mathrm{V}$, and $\mathrm{T}$ correspond, respectively, to equations $(4 a-c)$ while curve $M$ corresponds to the mean. These data show that the agreement is good for the central visual field, but not quite as good for the peripheral field. Nonetheless, each individual curve is within a factor of 2 of the mean out to $20^{\circ}$, and within a factor of 2.5 out to $80^{\circ}$. Linear cortical magnification would be even closer, going as the square root of these factors (namely, better than 1.4 and 1.6). Equation $(4 \mathrm{c})$ is based on the complete activity mapping of the central $10^{\circ}$ of several macaques, and may thus be considered particularly accurate. In the subsequent analyses this equation is used instead of the mean, since the 2 are nearly identical and use of equation (4c) facilitates mathematical computation.

Density of cytochrome oxidase (CO) puffs in $\mathrm{VI}$. The density of $\mathrm{CO}$ puffs (puffs $/ \mathrm{mm}^{2}$ ) was reported by Livingstone and Hubel (Fig. $17 \mathrm{C}$, 1984) as a function of the distance $D$ (in $\mathrm{mm}$ ) from the representation of $0^{\circ}$ eccentricity. To their data we fit a straight line with the following equation:

$$
\text { Puff density (puffs } \left./ \mathrm{mm}^{2}\right)=4.6+0.0643 \times D
$$

To express the equation as a function of eccentricity, the integral of the square root of the ACMF [equation (4c)] was solved to give distance $D$ (in $\mathrm{mm}$ ) as a function of eccentricity:

$$
D=12.2 \times[\ln (\text { Ecc }+0.94)]-[\ln (0.94)]
$$

Figure 4 shows distance $D$ (left-hand ordinate) as a function of eccentricity. Replacement of the $D$ term in equation (5) by equation (6) gives the corresponding densities of $\mathrm{CO}$ puffs (right-hand ordinate) as a function of eccentricity.

Visual-field area corresponding to a CO puff-centered module in VI. The product of ACMF $\left(\mathrm{mm}^{2} / \mathrm{deg}^{2}\right)$ and puff density (puffs $/ \mathrm{mm}^{2}$ ) gives values of puffs $/ \mathrm{deg}^{2}$. Since half of the puffs are primarily devoted to each eye, twice the reciprocal of this product provides the visual-field

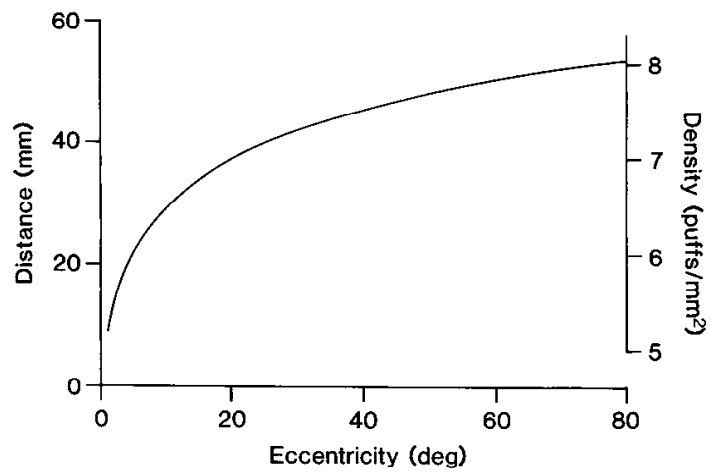

Figure 4. The distance from the foveolar representation (left-hand ordinate) and the density of cytochrome oxidase puffs (right-hand ordinate) in macaque V1 versus eccentricity. Distance (in $\mathrm{mm}$ ) corresponds to equation (6). Puff density corresponds to equation (5), based on I.ivingstone and Hubel (1984), and the distance, equation (6).

area (in $\mathrm{deg}^{2}$ ) corresponding to the area (in $\mathrm{mm}^{2}$ ) associated with a puff, if we assume that each $C O$ puff defines the center of such an area:

$$
\text { Visual-field area/puff }=2 /(\mathrm{ACMF} \times \text { puff density) }
$$

For brevity, we shall refer to a puff and its associated physical area as a "module" in V1. The visual-field area per puff (in $\mathrm{deg}^{2}$ ) is mathematically equivalent to the visual-field domain of a cortical module or puff. To obtain this cortical-module domain, curve CM-dom in Figure 5, equation (7) was solved with the ACMF term from equation (4c) and the puff density from equations (5) and (6). [If a V1 module were to include 1 "left-eye" puff and 1 "right-eye" puff, equation (7) would still be correct, as these 2 puffs would cover the same area of visual field.] The cortical area of a puff-centered module (in $\mathrm{mm}^{2}$ ) would be mathematically equivalent to the "cortical domain" of a puff.

Areas of receptive-field centers of $M$-like ganglion cells. Diameters of receptive-field centers of $\mathbf{M}$-like, broad-band ganglion cells are shown in de Monasterio and Gouras (Fig. 16, 1975). For these and newer data, A. P. Mariani, F. M. de Monasterio and E. P. McCrane (unpublished observations) fitted equations to the eccentricity dependence of the receptive-field-center diameter (in degrees) of these ganglion cells. While the data could be fit by different functions with different degrees of goodness-of-fit, they chose a linear fit, which was simple to use and yielded among the highest coefficients of correlation.

Equation (8) was obtained for the M-like ganglion cells $(\mathrm{RF}=$ receptive field):

$$
\text { M-cell RF diam. }=0.0367 \times(\mathrm{Ecc}+2.78)
$$

Receptive-field-center areas corresponding to these diameters are plotted in Figure 5, along with those of the dendritic-field (DF) area of $\mathbf{P}_{\alpha}$ cells (from Fig. 6A, Perry ct al., 1984). The receptive-field curve parallels the dendritic-field curve, the former being larger by a factor of $\sim 2$ (see Discussion). For comparison, Figure 5 also shows a curve of the visualfield domain of $M$ cells (the reciprocal of their density [equation (3)] along with the visual-field domain of a V1 module, described above.

The diameter of the receptive-field center of P-like ganglion cells changes very little with eccentricity in the central $10^{\circ}$ (de Monasterio and Gouras, 1975). The same is true for $P_{\beta}$ dendritic fields (Fig. 6B, Perry et al., 1984; see also Fig. 4, Rodieck et al., 1985). Nonetheless, no equation is presented for their receptive-field diameters because P-like ganglion cells may be a mixture of 2 anatomically and physiologically different cell types (Mariani et al., 1985; see also de Monasterio et al., 1975). Such a mixture may explain in part the relative scatter of $P$-cell receptive-field diameters with increasing eccentricity. In addition, diffraction may have affected measurements of the extremely small receptive-field centers of foveal $P$ cells (Campbell and Gubisch, 1966).

Point-image size in V1. The area of visual cortex activated by a point in visual space is called the point image (Mcllwain, 1975, 1976). To obtain the diameter of the point image in V1, Dow et al. (1981) combined 2 factors, the size and the scatter of receptive fields, and directly demonstrated a systematic increase with declining eccentricity. We have fitted, by eye, a straight line to the log-log plot of Figure 11 of Dow et al. (1981) in which eccentricity is in minutes of visual field:

Diam. of VI point image $(\mathrm{mm})=10^{[1.193-0.334 \times \log ([\mathrm{Ecc} / 60)]}$ 


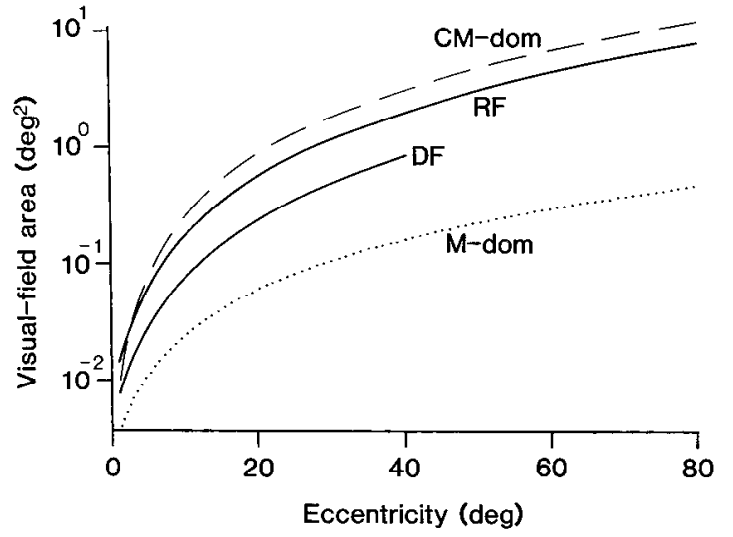

Figure 5. Visual-field areas $\left(\mathrm{deg}^{2}\right)$. The visual-field domain of a cortical module (dashed curve CM-dom), equation (7) of the text. Receptivefield area (curve $R F$ ) is based on equation (8) for the diameter of $\mathrm{M}$-cell receptive-field area. Dendritic-field area (curve $D F$ ) is based on a leastsquares fit to the diameter data in Figure 6A of Perry et al. (1984): Diameter $=0.00235 \times(\mathrm{Ecc}+3.25)$, with diameter and eccentricity (Ecc) in degrees. The visual-field domain of an $\mathrm{M}$ cell (dotted curve $M-d o m$ ) is given by the reciprocal of equation (3). All data are mean or pooled from the 2 hemiretinas.

The diameter of the point image is in the range of 1 to several $\mathrm{mm}$ (inset, Fig. 6), in essential agreement with Hubel and Wiesel (1974). Point-image area, computed assuming a circular area, is shown in Figure 6. (Van Essen et al., 1984, who did not separately account for the size and scatter of the receptive field, and assumed that multiunit measurements reflected both factors, reported much smaller sizes for point image in V1.)

Integration of magnification equations. To compute the area of V1, LeVay et al. (1985) integrated an ACMF equation [their equation (5)] over the visual field of the 2 eyes and computed $2120 \mathrm{~mm}^{2}$ of V1 per hemisphere. The visual field is a spherical surface. Their calculation was complicated by the fact that the border of the visual field is not a perfect circle (Polyak, 1957). A simpler, albeit less rigorous, method of integration assumes a circular border, but then the eccentricity (in degrces) of this border (the upper limit of integration in the integral) must be determined. We have done so by finding the upper limit that gives $2120 \mathrm{~mm}^{2}$ for the following integral:

$$
\begin{aligned}
& \text { Area of V1 }\left(\mathrm{mm}^{2}\right)= \\
& \qquad(180 / \pi)^{2} \times \int_{0}^{\text {border Ecc }} \pi \times \sin (\mathrm{Ecc}) \times \mathrm{ACMF} \times d(\mathrm{Ecc})
\end{aligned}
$$

Using equation (5) of LeVay et al. (1985) for the ACMF, the eccentricity of this border must be $73.6^{\circ}$ to achieve an area of $2120 \mathrm{~mm}^{2}$ from this integral. This eccentricity is very close to $72^{\circ}$, the mean for functional retina computed for the schematic human eye by Drasdo and Fowler (1974). (In the equation of LeVay et al., 1985, which intended to reproduce the ACMF of Ilubel and Freeman, 1977, 1.62 was erroneously given as the value for parameter $a$ [cf. equation (13), below]; the correct value is 1.71 [cf. equation (4a)]. The computed value for equation (4a), the correct version of the ACMF of Hubel and Freeman, 1977 , is then $2081 \mathrm{~mm}^{2}$.) Numerical integration of equation (10) gives 967 and $1525 \mathrm{~mm}^{2}$ for ACMF equations ( $4 \mathrm{~b}$ and $\mathrm{c}$ ).

As pointed out by Schwartz (1977), results of calculations based on a flat disk representation of the visual field closely approximate those based on the spherical representation (Rovamo and Virsu, 1984). With the disk representation, the sine of the eccentricity term in equation (10) would be replaced by eccentricity itself. Analytical solutions to integrals of this version of equation (10) are simple to obtain in that case. Using the version of the ACMF of Hubel and Freeman (1977) presented by LeVay et al. (1985) again, the upper limit of integration would have to be $64.8^{\circ}$ in order to compute their reported $2120 \mathrm{~mm}^{2}$. Then the areas computed for equations ( $4 \mathrm{~b}$ and c) would be 970 and $1524 \mathrm{~mm}^{2}$, almost exactly those given above. If, instead, the same upper limit of integration were used $-73.6^{\circ}-$ then the computed areas would

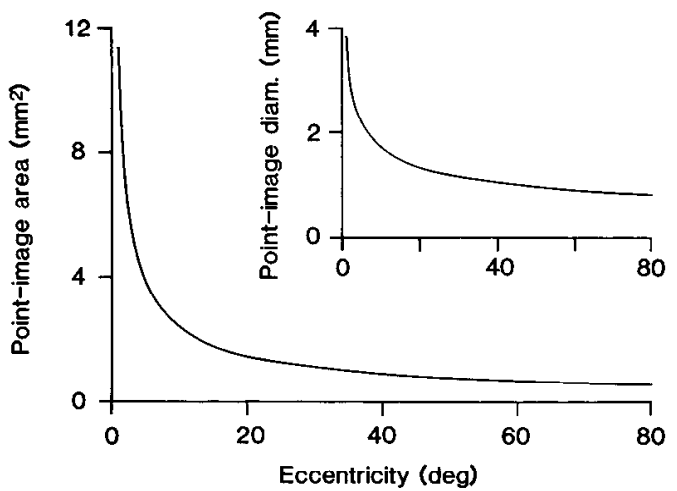

Figure 6. Point image, the area of V1 activated by a point stimulus, vcrsus eccentricity. This area is based on point-image diameter [equation (9)] (Dow et al., 1981) shown in the inset, and assumes a circular zone.

be 993 and $1582 \mathrm{~mm}^{2}$, also not much different from the values computed by the more rigorous method above.

The number of cells in the dLGN and its parvocellular and magnocellular compartments can be computed by replacing the ACMF term in equation (10) by equations (1) $(3)$, respectively. Using the same circular border of $73.6^{\circ}$ gives the numbers noted under dLGN cell densities, above. Because cell density is low at high eccentricity, increasing the border to $90^{\circ}$ would only increase the value of total cells by $6 \%$.

Limitations and assumptions. Several assumptions and limitations are implicit in this analysis. First, it is assumed that an equation can represent adequately its corresponding biological quantity. Unfortunately, the latter is almost never as precise as a simple equation. For example, there are across-animal variations (as much as 2-fold in the area of V1) and several sources of measuring and fitting error for the cortical and dLGN data for which necessarily incomplete data are available (cf. Van Essen et al., 1984). Nonetheless, the ACMF equations (4a-c) (Fig. 3)-obtained with different methods in different laboratories - show agreement within a factor of 3 in a quantity that ranges over 4 orders of magnitude. For these reasons, no unique significance should be assigned to the values computed below, except inasmuch as they are thought to be reasonable estimates of actual values.

Second, as pointed out by a reviewer in this journal, it is more than likely that all of the measurements on which this analysis is based have errors, and that the different parameters have significant normal variation. However, in almost every published data set, the confidence bounds are unavailable, and it is impossible for us to determine whether such uncertainties compound or cancel out one another. Hence, whenever possible, we have relied on multiple sources of data and their average. The absence of obvious inconsistences between the different data sets can be regarded as evidence that this approach is reasonable.

Third, an equation often carries the implication that the population studied is homogeneous. For example, equations (2) and (3) describe the $P$ and $M$ populations in dLGN. Even though it is convenient to treat each of these populations as uniform, both $P$ and $M$ cells encompass several varieties (Wiesel and Hubel, 1966; de Monasterio and Gouras, 1975; Marrocco et al., 1982). In additional, the assumption of uniformity carries with it the notion that a mean value is adequate to represent the behavior of all of the cells.

\section{Results}

\section{Retinal and geniculate cell densities}

The mapping of visual space onto striate cortex may be determined at the ganglion cell level (Clark, 1941; Bishop et al., 1962; Rolls and Cowey, 1970; Sanderson, 1971; Fischer, 1973; Wilson and Sherman, 1976; Drasdo, 1977; Schwartz, 1977, 1980; Tusa et al., 1978; Rovamo and Virsu, 1979). Ideally, the evaluation of such a peripheral scaling (Woolsey et al., 1942) would be based on the relationship between the cortical representation and the density of each ganglion-cell class as a function of eccentricity. While such systematic density values are not yet 

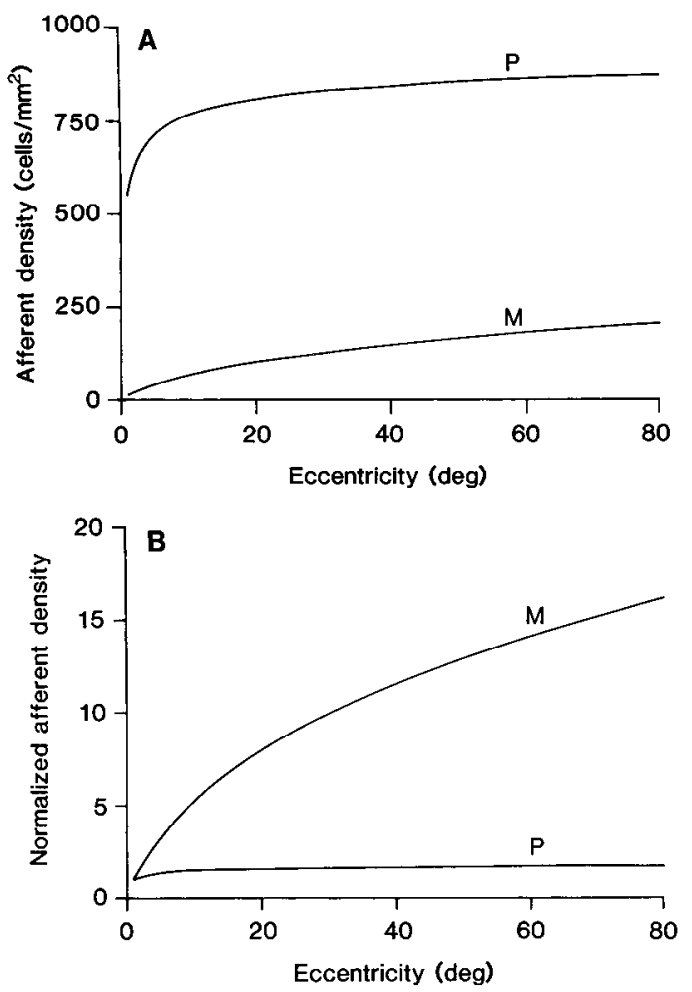

Figure 7. A, Afferent density of $\mathrm{P}$ and $\mathrm{M}$ cells onto $\mathrm{V} 1$ in macaque, based on equations ( $11 \mathrm{a}$ and $\mathrm{b}$ ), respectively, using the ACMF of equation (4c). $B$, Values of afferent density (for $\mathrm{P}$ and $\mathrm{M}$ cells) normalized to their respective values at $1^{\circ}$ eccentricity.

available for the 2 major classes of ganglion cells, color-opponent and broad-band, there are data on the density distribution of $\mathrm{dLGN} P$ and $M$ cells, neurons that are generally regarded as functional equivalents to those 2 respective ganglion cell classes. Averaging over ipsilateral and contralateral visual fields implies that half of the cells in each dLGN correspond to each eye. Of the ganglion cells in the ganglion-cell layer, $90 \%$ are reported to project to dLGN (de Monasterio and Gouras, 1975; Schiller and Malpeli, 1977; de Monasterio, 1978a, c; Perry et al., 1984; Perry and Cowey, 1984). These factors are incorporated into the densities shown in Figure 1A. Data from eccentricities lower than $5^{\circ}$ have been excluded (see Materials and Methods and Discussion).

The filled circles in Figure $1 B$ show, as a function of eccentricity, the ratio of dLGN-cell to ganglion-cell densities, the latter from Rolls and Cowey (1970). The open circles in Figure $1 B$ also show this ratio, but use the ganglion-cell data of Perry et al. (1984). The straight lines represent least-squares, linearregression fits to the 2 sets of data. The first set of ratios of Figure $1 B$ has a mean value of $1.075 \pm \operatorname{SD} 0.057(n=8)$ and shows a variation over eccentricity that is remarkably small, with a regressed slope of -0.0026 . The second set has a mean ratio of $0.737 \pm \operatorname{SD} 0.081(n=23)$ and also shows little variation over eccentricity, with a regressed slope of +0.0011 . Both regression lines show little change in the ratio of dLGN to ganglion cells that project to the dLGN, and what change is indicated is in opposite directions for the 2 sets of data.

Given the magnitude of the correction factors and experimental errors noted in the works of Rolls and Cowey (1970, p.
309), Perry et al. (1984, p. 1107), and Connolly and Van Essen (1984, pp. 555 and 561), the ratio of dLGN to ganglion cells that project to dLGN is likely to be constant and could be unity. Furthermore, the ganglion-cell densities presented in Figure $1 \mathrm{~A}$ use a single factor to convert distance to degree of visual field (e.g., $223 \mu \mathrm{m} / \mathrm{deg}$ for the open circles), but beyond about $40^{\circ}$ this conversion factor (CF) declines significantly (Perry and Cowey, 1985). Such a decline would only slightly increase the dLGN-ganglion-cell ratios shown in Figure $1 B$. The reason for this slight increase in the ratios is that while the ganglion-cell density in cells $/ \mathrm{deg}^{2}$ computed from density in cells $/ \mathrm{mm}^{2}$ declines as $\mathrm{CF}^{2}$ declines, the $\mathrm{dLGN}$-cell density depends on recomputed eccentricity and declines as $\mathrm{CF}^{1.9}$ [equation (1)].

Such a unity ratio is also indicated in the macaque by the ratio of optic nerve fibers, 1.2-1.8 $\times 10^{6}$ (Bruesch and Arey, 1942; Potts et al., 1972; Rakic and Riley, 1983), to total dLGN cells, 1.1-1.8 $\times 10^{6}$ (Clark, 1941; Chow et al., 1950), which is in the range $0.90-0.98$ when corrected by the finding that $\sim 10 \%$ of ganglion cells may not project to the dLGN (see above). A similar value obtains in the human visual system, where the ratio of optic nerve fibers to total dLGN cells (0.93), when corrected by the fiber ratio of optic nerve to combined crossed and uncrossed optic tract (1.09), is 1.01 (Kupfer et al., 1967; see also Chacko, 1948). We conclude from these observations that the more extensive dLGN-density data of Connolly and Van Essen (1984), providing separate values for $P$ and $M$ cells, can be used to describe the eccentricity dependence of the densities of the corresponding classes of ganglion cell as well.

\section{Mapping onto VI}

The hypothesis of peripheral scaling in macaque (cf. Clark, 1941), implying a constant ratio of $\mathrm{V} 1$ cells to their afferent retinal/ geniculate projections, can be tested. If we assume that the number of cells under $1 \mathrm{~mm}^{2}$ of $\mathrm{V} 1$ is roughly constant, the ACMF $\left(\mathrm{mm}^{2} / \mathrm{deg}^{2}\right)$ should be proportional to the ccllular magnification factor in V1 (cells/ $\mathrm{deg}^{2}$ ). For our purposes, then, we separately compared dLGN P-cell [equation (2)] and M-cell [equation (3)] densities to ACMF data to obtain the number of dLGN cells per area of VI (cells $/ \mathrm{mm}^{2}$ ), which we refer to as afferent density:

$$
\begin{aligned}
\text { P-afferent density } & =\mathrm{dLGN} \text { P-cell density/ACMF } \\
\text { M-afferent density } & =\mathrm{dLGN} \text { M-cell density/ACMF }
\end{aligned}
$$

There are several studies of ACMF as a function of eccentricity; the ACMF in equation (4c) will be used here (see Materials and Methods). Figure $7 A$ shows afferent densities of $\mathrm{P}$ cells (upper curve) and $M$ cells (lower curve). Figure $7 B$ shows these curves normalized to their value at $1^{\circ}$, in this case with $\mathrm{P}$ cells in the lower curve and $\mathrm{M}$ cells in the upper.

The afferent density of $\mathrm{M}$ cells increases steeply with increasing eccentricity, from $13\left(1^{\circ}\right)$ to $206\left(80^{\circ}\right)$ cclls $/ \mathrm{mm}^{2}$ of V1 (lower curve of Fig. $7 A$ ). This increase, by a factor of 16 (upper curve of Fig. $7 B$ ), indicates that V1 cortical magnification is unlikely to depend on a peripheral scaling mediated by the M-cell system. In contrast, the afferent density of $P$ cells is relatively constant with increasing eccentricity, varying from $550\left(1^{\circ}\right)$ to $872\left(80^{\circ}\right)$ cells $/ \mathrm{mm}^{2}$ of V1 (upper curve of Fig. $7 A$ ). This small difference, representing a factor of only 1.6 (lower curve of Fig. $7 B$ ), suggests that a peripheral scaling mediated by the P-cell system could be a major mechanism accounting for $\mathrm{V} 1$ cortical magnification (see below). 


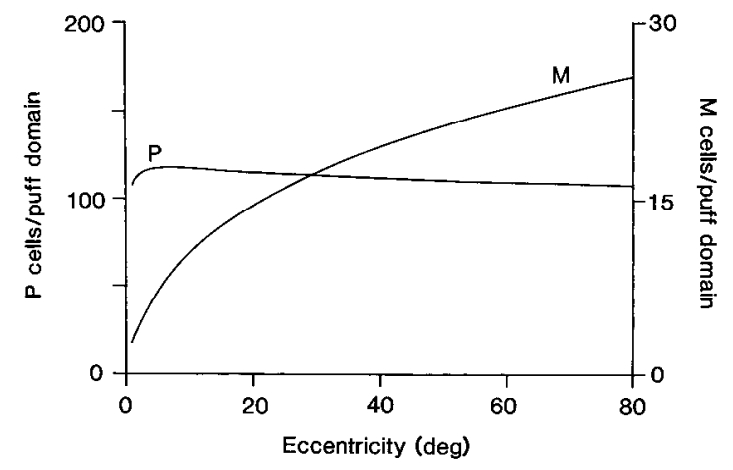

Figure 8. Afferent cells per puff-centered module in $\mathrm{V} 1$ of macque. $\mathrm{P}$ cells per puff [equation (12a)] (left-hand ordinate) is based on division of afferent density of $P$ cclls [cquation (2)/cquation (4c)] by puff density [equations (5) and (6)]. $M$ cells per puff [equation (12b)] (right-hand ordinate) is based on division of afferent density of $\mathrm{M}$ cells [equation (3)/equation (4c)] by puff density.

\section{Modular distribution}

The histochemical visualization of a regular pattern of vertical puffs of high cytochrome oxidase activity (Horton and Hubel, 1980, 1981; Humphrey and Hendrickson, 1980, 1983; Hendrickson et al., 1981; Horton, 1984) has provided an anatomical basis for the suggestion that area V1 of macaque cortex is composed of an array of functional units or modules (Hubel and Wiesel, 1977). If each CO puff were to define the center of a V1 module, the dimensions of such a module would be about $375 \times$ $550 \mu \mathrm{m}^{2}$ in the opercular region of V1 (Horton and Hubel, 1981; McCrane et al., 1982; Horton, 1984; Livingstone and Hubel, 1984), corresponding to a density of $\sim 5$ puff-centered modules/ $\mathrm{mm}^{2}$.

Horton (1984) and Livingstone and Hubel (1984) reported that puff density increased as a function of the distance from the foveolar representation. Consistent with this finding, LeVay et al., (1985) reported that the periodicity of pairs (left eye plus right eye) of ocular dominance stripes declined with eccentricity. We have converted the original data of Livingstone and Hubel (1984)-puff density (puffs $/ \mathrm{mm}^{2}$ ) as a function of distance [equation (5)]-into a function of eccentricity [equation (6)] and extrapolated the curve to greater eccentricities (Fig. 4). Thus, the number of dLGN cells $/ \mathrm{mm}^{2}$ of V1 may be expressed as cells per puff-centered module:

$$
\begin{aligned}
\mathrm{P} \text { cclls } / \text { puff } & =\mathrm{P} \text {-afferent density } / \text { puff density } \\
\mathrm{M} \text { cells } / \text { puff } & =\mathrm{M} \text {-afferent density } / \text { puff density }
\end{aligned}
$$

Figure 8 shows the numbers of $\mathrm{P}$ and $\mathrm{M}$ cells/puff-centered module. Again, the specific equations used are those that ultimately rely on the ACMF equation (4c): The afferent densities are from equations (11a and $b$ ), the puff density from equations (5) and (6).

Conversion of the P-cell afferent density to $\mathrm{P}$ cells/puff-centered module suggests a remarkable constancy in the latter value, varying only between 107 and 118 from $1^{\circ}$ to $80^{\circ}$ eccentricity (Fig. 8). In contrast, conversion of the M-cell data shows a 10fold increase of $\mathrm{M}$ cells/puff-centered module from $1^{\circ}$ to $80^{\circ}$ eccentricity (Fig. 8).

\section{Point-image area and afferent divergence}

Since the afferent density of $P$ cells is nearly constant, the absence of any dramatic change in the density of cells in layer $4 \mathrm{C} \beta$
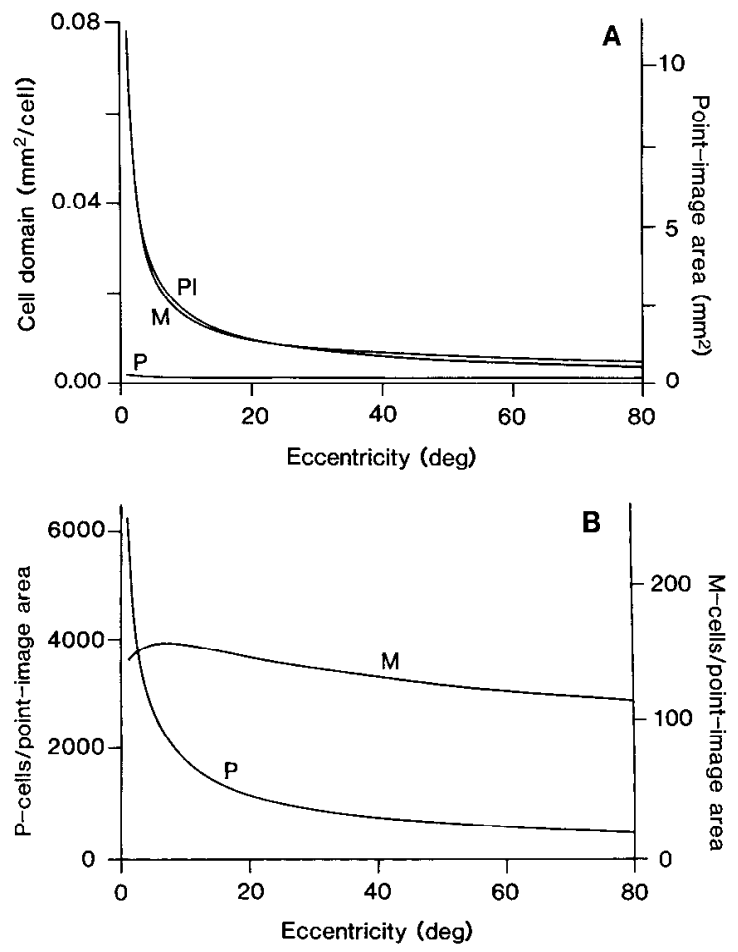

Figure 9. A, Cortical domains in $\mathrm{VI}$ of $\mathrm{P}$ and $\mathrm{M}$ cells compared to V1 point image. Cortical domains of $P$ and $M$ cells (left-hand ordinate) are equal to the reciprocal of their respective afferent densities. If the values of these curves were scaled to equal unity at $80^{\circ}$, the curves would represent the predicted relative divergence of $P$ cells onto recipient cells in layer $4 \mathrm{C} \beta$ of $\mathrm{V} 1$ and of $\mathrm{M}$ cells onto recipient cells in layer $4 \mathrm{C} \alpha$. Curve $P I$ (right-hand ordinate), showing point-image area in V1 versus eccentricity, is based on equation (9) for data from Dow et al. (1981). $B$, Number of $P$ cells per point image (left-hand ordinate) and of $M$ cells per point image (right-hand ordinate) in macaque V1 versus eccentricity. The numbers are based on division of the density of $P$ and $M$ cells [equations (2) and (3)] by the visual-field area corresponding to the cortical area of the point image [point-image area divided by equation $(4 c)]$.

(unpublished observations), the main parvocellular geniculorecipient layer (Hubel and Wiesel, 1972), suggests that the ratio of cortical P-recipient cells to $\mathrm{P}$ cells may be constant over eccentricity. If the ratio of cortical $\mathrm{M}$-recipient cells to $\mathrm{M}$ cells were also constant, the steep increase in $\mathbf{M}$-cell afferent density with eccentricity would require a corresponding increase in cell density in layer $4 \mathrm{C} \alpha$, the main magnocellular geniculo-recipient layer (Hubel and Wiesel, 1972). Since we have not observed such an obvious increase (unpublished observations), we conclude that $\mathrm{M}$ cells contact more layer $4 \mathrm{C} \alpha$-recipient cells in the central than in the peripheral visual field. The change in the number of recipient cells per afferent would follow the reciprocal of $\mathrm{M}$-cell afferent density, the dimensions of the latter being $\mathrm{mm}^{2}$ of V1 per $\mathrm{M}$ cell (curve $\mathrm{M}$ of Fig. $9 A$, left-hand ordinate). Mathematically, this quantity is the cortical domain in V1 of an $M$ cell, and if domain values for the $M$ curve were arbitrarily scaled to unity at $80^{\circ}$, this curve would represent the predicted relative divergence of $M$ cells onto recipient cells in layer $4 \mathrm{C} \alpha$ of $\mathrm{V} 1$.

The above conclusion is consistent with measurements of the point-image area, i.e., the maximal area of cortex capable of being activated by a stimulus located at a point in visual space (Mcllwain, 1975, 1976). To obtain this value for V1, Dow et 


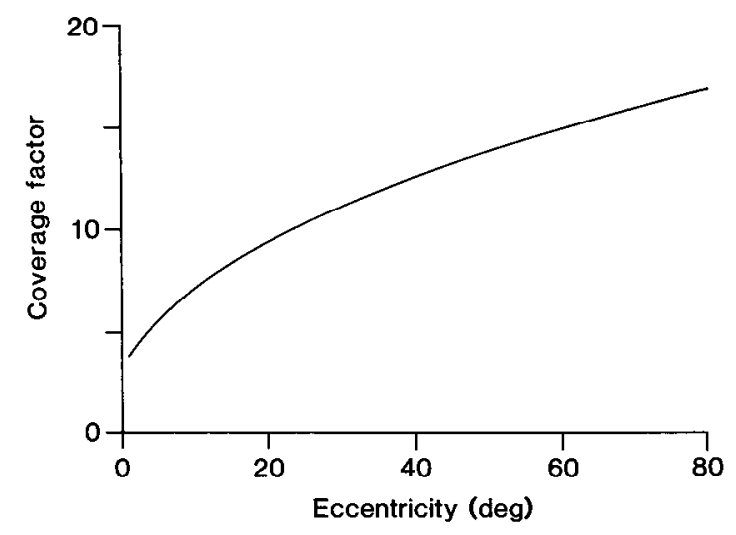

Figure 10. Coverage factor for $\mathrm{M}$ cells, computed by the product of M-cell density [equation (3)] and receptive-field-center area [equation (8)].

al. (1981) combined measurements of the size and scatter of receptive fields and showed that point-image size is greater for central than for peripheral visual fields. Equation 9 (inset of Fig. 6) fits the data of Figure 11 of Dow et al. (1981), the resulting point-image areas (in $\mathrm{mm}^{2}$ ) being shown in Figure 6. Pointimage area is also plotted in Figure $9 A$ (PI, right-hand ordinate), along with the domains of $M$ and $P$ cells (left-hand ordinate) noted above. The similarily of the $M$ and PI curves suggests that a constant number of $M$ cells may project to the area of a V1 point image. Indeed, the number of M-cell afferents per point-image area, given by the product of M-cell afferent density [equation (11b)] and point-image area, is nearly constant, $\sim 140$ (Fig. 9B, right-hand ordinate), or $70 \mathrm{M}$-cell afferents from each eye. Since P-cell afferent density is nearly constant, and pointimage area declines with eccentricity (Fig. 6), the number of $P$ cells/point-image area declines accordingly (Fig. $9 B$, left-hand ordinate).

\section{Receptive-field size and coverage factor}

The increase with eccentricity of the receptive-field-center area of broad-band ganglion cells (Fig. 5, curve RF) appears to be similar to, but not as steep as, that of the area of visual field corresponding to a CO puff-centered module in V1 (Fig. 5, curve CM-dom). The area of the field center of these M-like cells increases from $\sim 0.015 \mathrm{deg}^{2}$ at $1^{\circ}$ eccentricity to $\sim 1.9 \mathrm{deg}^{2}$ at $40^{\circ}$, and extrapolates to $\sim 7.2 \mathrm{deg}^{2}$ at $80^{\circ}$ [equation (8a); see also Fig. 16, de Monasterio and Gouras, 1975]. We calculate from equation (7) that the visual-field area of a puff-centered module corresponds to a domain of $\sim 0.010,3.0$, and $11 \mathrm{deg}^{2}$ at the same eccentricities. Curiously, the visual-field area of the receptive-field center of the M-like, broad-band ganglion cells thus seems to approximate that of its corresponding puff-centered V1 module.

Since there is more than $1 \mathrm{M}$ cell per puff-centered module, the similarity of these areal values implies that there may be a marked overlap of the field centers of $M$ cells projecting to a given puff. The degree of such an overlap would increase with eccentricity, since the number of $\mathrm{M}$ cells/puff increases 10 -fold, from 2.5 at $1^{\circ}$ to 25 at $80^{\circ}$ eccentricity [equation (12b), Fig. 8]. Formally, we can compute the retinal coverage factor, i.e., the average number of cells whose receptive-field center includes the same point in visual space. The coverage factor is identical to the "overlap," i.e., the average number of cells whose recep- tive fields cover that of a given cell (Fischer, 1973; Cleland et al., 1975; Wassle et al., 1981a, b). This factor is the product of cell density ( 1 retina's worth of $M$ cells) and receptive-fieldcenter area.

The coverage factor for $\mathrm{M}$ cells (Fig. 10) increases gradually from 4 at $1^{\circ}$ to 17 at $80^{\circ}$ eccentricity. This 4 -fold increase is less than the 10 -fold one suggested above because the visual-field domain of a cortical module increases slightly more with eccentricity than does the $\mathrm{M}$-cell receptive-field area. If on-center and off-center $M$ cells were regarded as separate subclasses, the coverage factor for each, increasing from 2 to 8.5 , would still completely cover all of the visual field at all eccentricities.

\section{Discussion}

Mapping of ganglion cells onto dLGN

Our analysis strongly suggests an essentially unity ratio between ganglion cells and dLGN cells. We have formally made the case for such a relationship only for eccentricities beyond $5^{\circ}$, since density values for ganglion cells within the central region are uncertain (but see below). This conclusion is based only on data from neurons of the ganglion-cell layer, data corrected for the finding that $\sim 10 \%$ of the ganglion cells do not project to the dLGN (Schiller and Malpeli, 1977; de Monasterio, 1978a, c; Perry and Cowey, 1984). Thus, displaced ganglion cells in the inner nuclear layer (Polyak, 1941) have not been included in our analysis.

A unity ratio of dLGN to ganglion cells is at variance with the speculation of Malpeli and Baker (1975), who suggested that the ratio of dLGN to ganglion cells varied from more than unity towards the fovea to less than unity towards the periphery. However, their measurements were of volume of dLGN/deg ${ }^{2}$ of visual field rather than of actual cell density. In addition, their speculation was criticized by Rovamo and Virsu (1979) for its reliance on an ACMF derived from the study of a mixture of animals (Daniel and Whitteridge, 1961) and for its reliance on the retinal cell-density data of Rolls and Cowey (1970), which, for the central $5^{\circ}$, were based on counts of cones rather than of ganglion cells.

We excluded from our analysis the centralmost ganglion-cell densities reported by Rolls and Cowey (1970) and Perry et al. (1984). In the former study, as noted above, such counts were based on cones, rather than ganglion cells. In the latter study, the many sublayers of ganglion cells in central retina made counts from whole-mount preparations less accurate. More important, the lateral displacement of both foveal and parafoveal ganglion cells with respect to the location of their corresponding concs invalidates in central retina the direct application of the factor (e.g., $223 \mu \mathrm{m} / \mathrm{deg}$ ) used to convert linear distance to degrees of visual field. As indicated by Missotten (1974), in central retina the area covered by the cone pedicles in the outer plexiform layer is several times larger than that covered by the cone inner segments themselves. Thus, the direct application of the above conversion factor for this region leads not only to a disparity between the computed and the true visual-field positions (in degrees), but also to an error in the conversion of density in cells $/ \mathrm{mm}^{2}$ to density in cells $/ \operatorname{deg}^{2}$ (S. J. Schein, unpublished observations; F. M. de Monasterio and E. P. McCrane, unpublished observations).

Consider, for instance, the $0.5 \mathrm{~mm}$ data of Perry et al. (1984). Direct conversion by $223 \mu \mathrm{m} / \mathrm{deg}$ of this eccentricity and its mean cell density $\left(33,500\right.$ ganglion cells $\left./ \mathrm{mm}^{2}\right)$ would give $2.24^{\circ}$ 
and $1665 \mathrm{cells} / \mathrm{deg}^{2}$. To judge from the schematic diagram of Missotten (Fig. 1, 1974) for a ganglion cell located at $0.5 \mathrm{~mm}$, there is a displacement of $\sim 350 \mu \mathrm{m}$ from its cone(s), whose visual-field position(s) we estimate as $\sim 0.75^{\circ}$. The inner segment of such a cone would be within the diagram's 60-200 $\mu \mathrm{m}$ range, and the corresponding cone pedicle (as well as the underlying ganglion cell) would be within the diagram's 300-650 $\mu \mathrm{m}$ range. The resulting linear expansion from cone inner segments to cone pedicles would be $\sim 2.5$, giving an areal expansion of $2.5^{2}$, or about 6 . Inasmuch as this estimate from human retina could be applied to density measurements in macaque, the corrected eccentricity in the visual field for the $0.5 \mathrm{~mm}$ data of Perry et al. (1984) would be $\sim 0.75^{\circ}$, and the corrected density $\sim 10,400$ cells $/ \mathrm{deg}^{2}$.

Similarly, the $1.0 \mathrm{~mm}$ data of Perry et al. (1984), showing a density of 31,250 cells $/ \mathrm{mm}^{2}$, would directly convert to $4.5^{\circ}$ and 1554 cells $/ \mathrm{deg}^{2}$. Given the lateral displacement of $500 \mu \mathrm{m}$ from their corresponding cones and an areal correction of 2.25 , the corrected eccentricity in the visual field would be $\sim 2^{\circ}$, and the corrected density would be about 3500 cells $/ \mathrm{deg}^{2}$.

Taking into account that $10 \%$ of ganglion cells does not project to dLGN (see Materials and Methods), the above values must be adjusted to 9360 ganglion cells/ $/ \mathrm{deg}^{2}$ at $0.75^{\circ}$ and 3150 ganglion cells $/ \mathrm{deg}^{2}$ at $2^{\circ}$. Integration of the equation for dLGN-cell density, in Table 1 of Connolly and Van Essen (1984), over the central $2.5^{\circ}$ gives their stated number of dLGN cells; thus for these central eccentricities the 1.31 correction factor incorporated in equation (1) must be removed. Then, $1 / 2$ of equation (1)/ 1.31 yields dLGN cell densities corresponding to 1 eye of 10,450 cells $/ \mathrm{deg}^{2}$ at $0.75^{\circ}$ and 4160 cells/ $/ \mathrm{deg}^{2}$ at $2^{\circ}$ eccentricity. Compared to the above estimates, these values provide geniculate-to-ganglion cell ratios between 1.1 and 1.3. While we do not claim to have proven a unity ratio between ganglion cells and their corresponding dLGN cells of the foveal representation, these ratios are certainly consistent with such a possibility.

Recently, Perry and Cowey (1985) compared cells/deg in retina and dLGN, using the density data of Perry et al. (1984) and of Connolly and Van Essen (1984). They concluded that the ratio of these cells was neither unity nor constant. They reported that their (P-like) " $\mathrm{P}_{\beta}$ cells of the central retina show a greatly expanded representation in the parvocellular layers of the dLGN, whereas there is compression peripherally." These conclusions are open to several objections. First, the eccentricities and cell densities of the ganglion-cell data were not corrected for the displacement of foveal ganglion cells. As noted above, failure to perform this correction yields erroneously low densities of ganglion cells and severalfold overestimates of the ratio of dLGN to ganglion cells. This error could explain their claim of great expansion for central $\mathrm{P}_{\beta}$ cells in their geniculate representation. Second, as noted in Materials and Methods (Ganglion-cell Densities), in order for the geniculate-density equations of Connolly and Van Essen (1984) to give the reported cell totals outside of the fovea, correction by a factor of 1.31 is required. Failure to correct for this factor may explain Perry and Cowey's (1985) claim of compression in the dLGN's representation of peripheral $\mathbf{P}_{\beta}$ cells.

Perry and Cowey (1985) also concluded that their (M-like) $\mathrm{P}_{\alpha}$ cells "show compression at all eccentricities." They assumed that $\mathrm{P}_{\alpha}$ cells represented a constant fraction (10\%) of ganglion cells, independent of eccentricity. As discussed in detail below, this assumption is unsupported by data in the central $10^{\circ}$. Were the $\mathbf{P}_{\alpha}$-cell fraction to decrease with decreasing eccentricity, as suggested by other data (see below), use of a constant fraction would overestimate the densities of these cells in central retina and therefore partially compensate for their failure to correct for foveal displacement. This problem for central retina, and the omission of the 1.31 correction of the dLGN equations for peripheral retina, could explain their finding of compression at all eccentricities.

Thus, on the basis of the same data used by Perry and Cowey (1985), we have reached the opposite conclusions. In their paper, they also reported totals for 2 retinas of $1.4 \times 10^{6}$ and $1.8 \times 10^{6}$ ganglion cells. After correction by $90 \%$ to give the number of cells projecting to dLGN, and comparison of these values to the total number of cells in dLGN, these data provide further support for our arguments for a unity ratio (see Results).

\section{$A C M F$ and V1 area}

Clark (1941) reported $1445 \mathrm{~mm}^{2}$ for the Vlarea on 1 side, and Daniel and Whitteridge (1961) reported $1400 \mathrm{~mm}^{2}$. In a more recent study of 31 striate cortices, Van Essen et al. (1984) reported measurements of the Vl area from 690 to $1560 \mathrm{~mm}^{2}$, with an average of $1200 \mathrm{~mm}^{2}$. Integration of the ACMF equation (see Materials and Methods) gives the total area of striate cortex. Equation (4c), representing the mean of the ACMFs of Hubel and Freeman (1977), Van Essen et al. (1984), and Tootell et al. (1982), specifies an area of $1525 \mathrm{~mm}^{2}$, which is at the high end of the above range but close to that reported by Clark (1941) and Daniel and Whitteridge (1961).

Most reports of cortical magnification in V1 (Hubel and Freeman, 1977; Schwartz, 1977, 1980, 1983; Tootell et al., 1982; Dow et al., 1985; LeVay et al., 1985) provide equations of the form of equation (13), in which the scaling factor $k$ for linear magnification becomes $k^{2}$ in the areal version:

$$
\text { Areal magnification }\left(\mathrm{mm}^{2} / \mathrm{deg}^{2}\right)=k^{2} \times(\mathrm{Ecc}+a)^{-2.0}
$$

Computed V1 area depends on $k^{2}, a$, and the exponent. The area increases directly with $k^{2}$. Variation in $a$ could have a major effect, but recent values for $a$ have stabilized around $0.8^{\circ}$. Its value is 0.78 in equation (4b) and $0.94^{\circ}$ in equation (4c). The most intensive mapping of central representation in $\mathrm{Vl}$ is by Dow et al. (1985), who reported a value of $0.33^{\circ}$. However, Levi et al. (1985) reanalyzed the mapping data from each individual monkey in Dow et al. (1985) and concluded that 0.77 was a better estimate of $a$.

Dow et al. (1981) used a third degree polynomial instead of an equation of the form of equation (13). Figure 6 of Dow et al. (1981) is a composite of their and others' data, including those of Daniel and Whitteridge (1961) and Hubel and Freeman (1977). The polynomial equation they fitted to the points produced a curve that was quite different from that reported by Schwartz (1983) for the same composite data. Also, the magnification data of Daniel and Whitteridge (1961) originated from different species, and no equation to fit those data was provided by the authors. For these reasons we did not use the polynomial equation of Dow et al. (1981). We note, however, that the curves of these equations are largely contained within the envelope of curves in Figure 3. An exponent of -2.0 was adopted in subsequent work (Dow et al., 1985) for data that were also exclusively from the central $2.5^{\circ}$. From mapping of a single monkey, Van Essen et al. (1984) presented an equation similar to equation (13), except for an exponent of -2.2 instead of 2 . However, an exponent of -2.0 was adopted in subsequent work (cf. LeVay et al., 1985).

\section{Peripheral scaling}

The range of the number of $P$ cells for hoth eyes for 1 hemifield is $88 \%$ (Clark, 1941; Connolly and Van Essen, 1984) of the 1.1$1.8 \times 10^{6}$ cells in $1 \mathrm{dLGN}$ (Clark, 1941; Chow et al., 1950). The area of V1 in a single hemisphere ranges from 690 to 1560 $\mathrm{mm}^{2}$. Pairing the low dLGN with the high $\mathrm{V} 1$ area values gives $620 \mathrm{P}$ cells $/ \mathrm{mm}^{2}$, a value close to that of Figure $7 A$, which used 
a relatively small number of $P$ cells and a relatively large $V 1$. Adopting instead the mean P-cell value ( $88 \%$ of $\left.1.45 \times 10^{6}\right)$ and $1200 \mathrm{~mm}^{2}$ as the mean V1 area of each hemisphere (Van Essen et al., 1984) gives $1063 \mathrm{P}$ cells $/ \mathrm{mm}^{2}$. Clark (1941), who was the first to suggest peripheral scaling of V1 according to geniculate-cell density, estimated an afferent density of $1200 \mathrm{P}$ cells $/ \mathrm{mm}^{2}$ on the basis of the zone of degeneration in dLGN resulting from a single lesion in V1 of macaque.

We have suggested that P-cell afferent density increases by only 1.6 from $1^{\circ}$ to $80^{\circ}$ eccentricity (Fig. $7 A$ ). This conclusion is independent of the choice of $k$ in the ACMF equation; it would be affected, however, by the choice of exponent. For P-cell density [equation (2)], the exponent is -1.96 , so an exponent of -2.0 in the ACMF equation gives a nearly parallel eccentricity dependence. By contrast, Connolly and Van Essen (1984) computed a quantity similar to afferent density and reported a 4-fold increase with eccentricity. This discrepancy is primarily due to their use of $a-2.2$ exponent in their ACMF equation, an exponent estimated for a single monkey. The resulting difference in exponents is responsible for the 2.5 -fold difference in the corresponding calculations of afferent density at $80^{\circ}$ eccentricity.

Webb and Kaas (1976) compared linear cortical magnification to ganglion-cell density in the owl monkey and concluded that there was peripheral scaling. A reanalysis of those data using matched (areal) dimensions for both quantities led Myerson et al. (1977) to reject that conclusion. Peripheral scaling is supported, however, for the cat (Bishop et al., 1962; Sanderson, 1971; Albus, 1975; Wilson and Sherman, 1976; Tusa et al., 1978) and for man (Drasdo, 1977; Rovamo and Virsu, 1979). Rolls and Cowey (1970) drew what we believe to be the correct conclusion for the macaque, viz., that ganglion-cell density and cortical magnification are proportional. Strictly, however, this conclusion was based on (1) the dimensionally mismatched comparison of linear magnification against ganglion-cell density and (2) the assumption that, in the central $7^{\circ}$, such a density could be estimated from that of cones.

The nearly constant afferent density of $\mathrm{P}$ cells indicates that the area of $V 1$ is proportional to the density of $P$ cells in dLGN, which provides evidence for peripheral scaling between these 2 visual structures. In addition, our finding of an essentially unity ratio between geniculate and ganglion cells, and implicitly between dLGN P cells and (P-like) ganglion cells (which represent $\sim 80 \%$ of the total at both levels) implies peripheral scaling from $\mathrm{P}$-like ganglion cells in retina to $\mathrm{Vl}$.

This conclusion is at variance with that of Perry and Cowey (1985), who claimed that "there is no simple relationship bctween ganglion cell density and the cortical magnification factor" of macaque. Their claim was based on the incongruence between the cumulated curves of ganglion cells and V1 area. However, this incongruence may be explained by their failure to compensate for the foveal displacement of ganglion cells (see above), which would alter the actual shape of the curve of cumulated ganglion cells.

\section{The P-cell module}

If $\mathrm{CO}$ puffs in V1 were to define the centers of modules, then the number of $\mathrm{P}$ cells corresponding to a module in V1 would show little variation with eccentricity (Fig. 8). Within the same eccentricity range, the number of $M$ cells per module would vary markedly, over a 10 -fold range. Hence, the module defined by the CO puffs may be more accurately termed a "P-cell module." Our findings thus support a novel hypothesis of peripheral scaling, in which Vl cortical magnification is based on the mapping of a relatively constant number of just 1 class of afferent, the $\mathrm{P}$ cells, onto a V1 module, rather than of all afferent cells onto cortical area.

As implied in the previous section, our estimate of the number of $P$ cells per puff-centered module, $\sim 110$, is probably at the low end of the range. While the constancy of this value would be unaffected by a change in the $k$ and $a$ parameters of the standard magnification equation [equation (13)], the actual computed value is itself very sensitive to these parameters. We have obtained 2 other estimates of the number of $P$ cells per module, estimates that depend on the above constancy. First, as described above, integration of the ACMF of equation (4c) gives an area for both striate cortices of $3050 \mathrm{~mm}^{2}$. There are between $\sim 5$ and $7.5 \mathrm{puffs} / \mathrm{mm}^{2}$ (Fig. 4), so the total number of puffs should be between 15,250 and 22,875. For formal integration over a spherical visual field with a circular border at $73.6^{\circ}$, equation (14), we used equation (4c) for ACMF and equations (5) and (6) for puff density, and found a total number of 19,998 puffs, or 10,000 puffs per eye for the whole visual field:

$$
\begin{aligned}
& \text { Total number puffs }=\left(\frac{180}{\pi}\right)^{2} \times \\
& \int_{0}^{73.6^{\circ}}[\pi \times \sin (\mathrm{Ecc}) \times \mathrm{ACMF} \times \text { Puff dens. } \times d(\mathrm{Ecc})]
\end{aligned}
$$

If the total number of $P$ cells in one dLGN is $88 \%$ of $1.1-1.8 \times$ $10^{6}$ (Chow et al., 1950; Clark, 1941, respectively), then a range of $97-158 \mathrm{P}$ cells per puff is obtained.

Second, the above integration establishes an overall mean puff density of $\sim 6.56 \mathrm{puffs} / \mathrm{mm}^{2}$. Adopting $2400 \mathrm{~mm}^{2}$ as the mean area of both striate cortices (Van Essen et al., 1984), the number of puffs would be 15,744 , giving 7872 puffs per eye for the whole visual field. Then, if $88 \%$ of $1.45 \times 10^{6}$ were adopted as the mean number of $P$ cells, the number of $P$ cells per puff would be 162 .

Sakitt and Barlow (1982) proposed that the number of inputs required to provide an economical encoding of visual spatial information in human V1 is 256 cells per "module," covering $180^{\circ}$ of orientation preference. However, a puff-centered module spatially encodes less than $180^{\circ}$ of orientation preference (Blasdel and Salama, 1986; R. Tootell, personal communication). If, for example, $90^{\circ}$ on average were encoded, then twice our estimate of the number of P-cell afferents per module would be very similar to the 256 suggested by Sakitt and Barlow (1982).

\section{A P-cell submodule?}

$\mathrm{CO}$ histochemistry has also demonstrated a striking honeycomb pattern in tangential sections of V1 at the level of layer 4A (McCrane et al., 1982; Horton, 1984). In an autoradiographic study using orthograde transport of amino acids, such a pattern was previously shown for the dLGN projection of the parvocellular layers onto layer 4A (Hendrickson et al., 1978). Since there are about 10 honeycomb units within the area of a puffcentered module (McCrane et al., 1982), each of these units could correspond to an average parcel of 10-15 afferents of the $\sim 100-150 \mathrm{P}$ cells per module. Retinal recordings show that the 
"blue-center" ganglion cells represent 6-10\% of all central coloropponent cells (de Monasterio and Gouras, 1975; de Monasterio, 1978a, 1979), and that the very large majority of "bluecenter" cells, unlike other ganglion cells, is on-center (Malpeli and Schiller, 1978; de Monasterio, 1979). If a minimal complete set of P-like cells were to require 1 blue-on-center cell outside of the "tritanopic" area of the fovea (Wald, 1967; de Monasterio et al., 1981, 1985; Williams et al., 1981), the preceding physiological studies indicate that such a set could consist of 10-17 cells - a value consistent with the anatomical estimate of 10-15 $P$ cells per honeycomb unit. The preceding speculations imply that the honeycomb unit of layer $4 \mathrm{~A}$ might anatomically represent a submodule of cortex in a 1-to-1 relationship with a minimal complete set of P-like cells.

\section{V1 Point image: a consequence of $M$-cell mapping?}

A fairly constant number of $M$-cell afferents from each eye, $(\sim 70)$, corresponds to the area of the V1 point image. In contrast, this number varies over a 10 -fold range for the P-cell system. The $\mathrm{Vl}$ point image thus may represent a basic unit of $\mathrm{M}$-cell function, analogous to the $\mathrm{CO}$ module as a basic unit of P-cell function. Our suggestion implies that the point-image measurements of Dow et al. (1981) and of Hubel and Wiesel (1974) were a consequence of the M-cell projection onto V1. In retrospect, such a suggestion should not be surprising, since their measurements of point image depended on the largest receptive fields, and those of $M$ cells are much larger than those of $P$ cells (de Monasterio and Gouras, 1975). Note, however, that since cells in different cortical layers have different receptive-field areas, characterization of individual layers might demonstrate the existence of a multiplicity of point-image areas at any eccentricity (Mcllwain, 1976).

The prediction that a foveal $\mathrm{M}$ cell will contact more neurons in layer $4 \mathrm{C} \alpha$ of $\mathrm{V} 1$ than a peripheral $\mathrm{M}$ cell may explain the change in soma size of $\mathrm{M}$ cells, from larger in posterior dLGN to smaller in anterior dLGN (Von Noorden and Middleditch, 1975). Conversely, constant divergence of $P$ cells is consistent with the absence of such a soma-size gradient for $P$ cells.

The overall greater divergence of $M$ than of $P$ cells onto recipient cells in layer $4 \mathrm{C}$ may also explain the observation of Killackey and Snyder (1973), who found that the minimal size of V1 lesions producing visible degeneration in the magnocellular layers of dLGN was considerably larger than that in parvocellular layers. At least at the one eccentricity that Blasdel and Fitzpatrick (1984) studied, the receptive-field size of $4 \mathrm{C} \alpha$ neurons was much larger than that of $4 C \beta$. Such a disparity is presumably based on the larger terminal arbors of $M$ than $P$ cells (Blasdel and Lund, 1983), as the dendritic fields of cells in layer $4 \mathrm{C} \alpha$ and $4 \mathrm{C} \beta$ have similar lateral spreads (Lund, 1973). More than a single eccentricity would have to be studied to test directly our divergence predictions.

\section{Nonuniformity of $M$-cell mapping}

The conclusion that $\mathbf{M}$ cells do not map uniformly onto V1 is predicated on the finding of Connolly and Van Essen (1984) of a differential variation of $\mathrm{P}$ - and $\mathrm{M}$-cell densities with eccentricity. Since $\mathrm{P}$-cell density parallels ACMF, M-cell density must as a consequence fail to do so.

A few studies have not found such a differential variation. On the basis of recordings from axons of ganglion cells, Schiller and Malpeli (1977) found little variation with eccentricity in the relative numbers of $M$ and $P$ cells. More recently, using dendritic-field size to separate the (M-like) $\mathrm{P}_{\alpha}$ cells from the (Plike) $\mathrm{P}_{\beta}$ cells, Perry et al. (1984) reported that the $\mathrm{P}_{\alpha}$ cells were a roughly constant fraction of the ganglion cells - between 8 and $12 \%$ (their Table 1).

Other anatomical evidence, however, supports such a differential variation. Cell-density measurements in the dLGN (Connolly and Van Essen, 1984) show that the ratio of $M$ to $P$ cells rises steeply with eccentricity (inset, Fig. 2), the greatest increase being found within the central retina. In fact, the fractions reported by Perry et al. (1984) were taken from data for 2.3-10.6 $\mathrm{mm}$, with most of the measurements around $6 \mathrm{~mm}$. These distances correspond to $10.3^{\circ}, 47.5^{\circ}$, and $26.9^{\circ}$ if a strict $223 \mu \mathrm{m} /$ deg conversion is assumed. Using equations (2) and (3), derived from Connolly and Van Essen (1984), and taking into account that $\sim 10 \%$ of ganglion cells are neither M-like nor P-like (Schiller and Malpeli, 1977; de Monasterio, 1978a, c; Perry et al., 1984), we calculate that $M$ cells are $7.4,14.2$, and $11.4 \%$ of the total at the above eccentricities. These values are close to those of Perry et al. (1984), lending support to the data of Connolly and Van Essen (1984) in the $10^{\circ}-47^{\circ}$ eccentricity range. Lacking data for the central $10^{\circ}$, Perry et al. (1984) may have missed the zone of greatest change. If this suggestion is correct, it would invalidate any conclusions based on the assumption that there is a constant ratio of $\mathrm{M}$ to $\mathrm{P}$ cells, independent of eccentricity (e.g., Perry and Cowey, 1985).

Accumulated electrophysiological evidence also supports a differential variation. Ogden and Miller (1966) recorded antidromic mass potentials at different locations around the optic nerve head. They found fast (M-cell) and slow (P-cell) components from fibers representing peripheral retina, but essentially only the slow component from fibers representing central retina. Later, Gouras (Fig. 7, 1969) reported that antidromic, graded intraretinal potentials recorded at the periphery exhibited a conspicuous, early (M-cell) wave, while at the fovea a later (P-cell) wave became more prominent. More recently, de Monasterio and Gouras (1975) found a steep rise in the ratio of $M$ to $P$ cells with eccentricity, and confirmed this finding in a later report (de Monasterio, 1978a). Indeed, recording from the soma of ganglion cells, Schiller and Malpeli (1977) also found a steep increase with eccentricity in the $\mathrm{M} / \mathrm{P}$-cell ratio.

\section{Coverage of retina by $M$ cells}

The receptive-field coverage factor defined by Wassle et al. (1981a, b), which is the same as the overlap defined by Fischer (1973), is equal to the average number of cells whose receptiveficld center includes the same point in visual space, analogous to the number of afferents corresponding to the cortical point image (McIlwain, 1975, 1976). Our coverage factor calculations suggest that the number of $\mathrm{M}$-like ganglion-cell field centers activated by a point in visual space is between 4 and 17 for 1 eye. In the case of uniformly distributed cells with a high coverage factor, the point stimulus activates an aggregate receptive field whose radius approaches the diameter of an individual receptive field, that is, an area that would correspond to 4 times as many $M$ cells. A similar expansion could occur at the level of the cortex (layer $4 \mathrm{C} \alpha$ for $\mathrm{M}$ cells), resulting in a zone activated by a point stimulus in V1 that corresponds to as many as 16 times as many M-like ganglion cells. Additional expansion of the activated zone could be due to intracortical connections to cortex beyond the domains of the afferent $M$ cells. We find that 

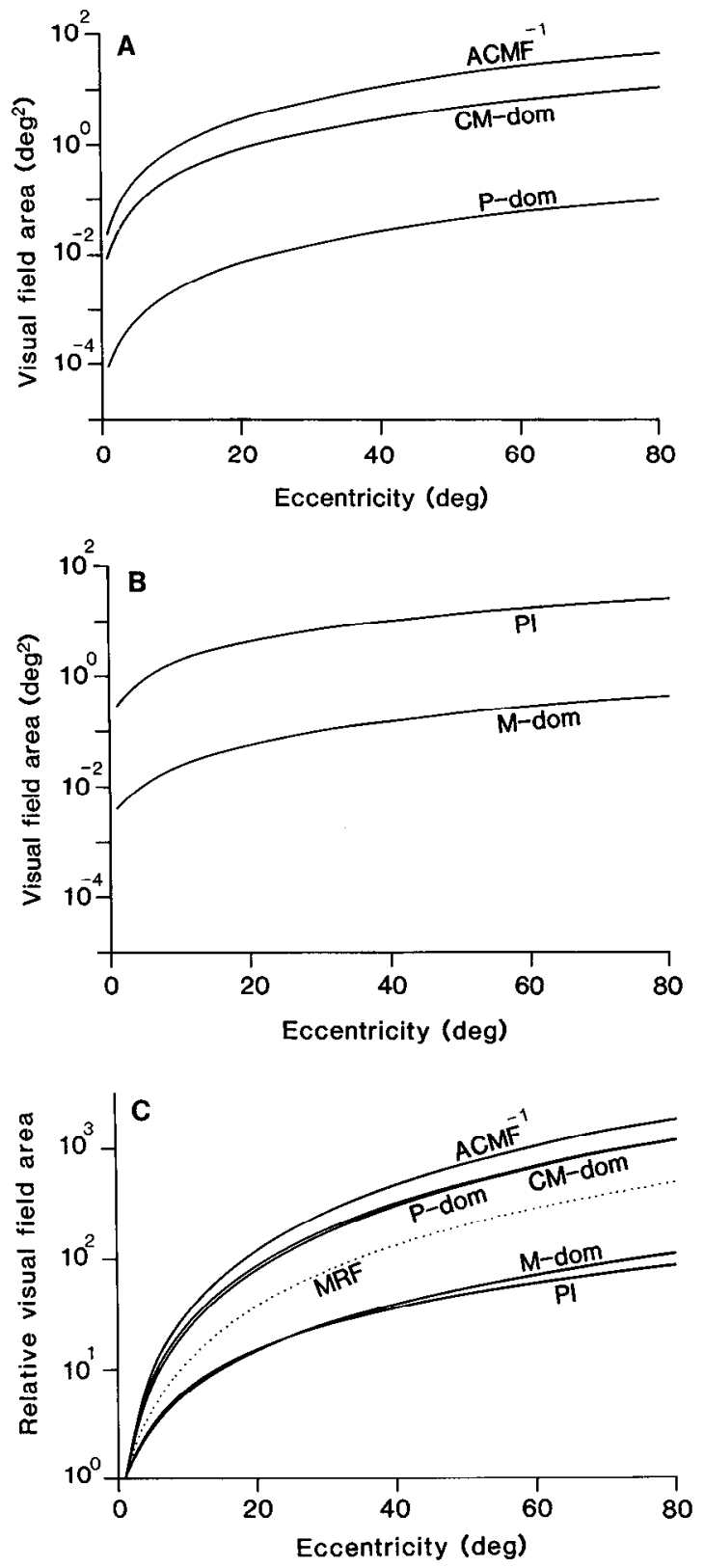

Figure 11. A, Eccentricity dependence of the visual-field domain of $\mathbf{P}$ cells $(P-d o m)$, of puffs or cortical modules in V1 $(C M-d o m)$, and a 1 $\mathrm{mm}^{2}$ visual-field area of $\mathrm{V} 1\left(A C M F^{-1}\right)$; all quantities in $\mathrm{deg}^{2} . B, \mathrm{Ec}$ centricity dependence of the visual-field domain of $\mathrm{M}$ cells $(M-d o m)$ and the visual-field area corresponding to the point image in Vl $(P I)$; both quantities in $\mathrm{deg}^{2}$. $C$, Eccentricity dependence of all of the functions in $A$ and $B$ but with the curves normalized to equal $10^{\circ}$ at $1^{\circ}$, along with that of the receptive-field center of $\mathrm{M}$ cells $(M R F)$.

the area of $\mathrm{V} 1$ activated by a point stimulus corresponds to about $70 \mathrm{M}$ cells from each eye (one-half of $140 \mathrm{M}$ cells/pointimage area), a value requiring an 18 -fold total expansion for central, but only a 4 -fold expansion for peripheral retina.

If the receptive-field area of a cell were equal to its visualfield domain, then the coverage would be unity; thus, a receptive field $n$ times as large gives a coverage of $n$. In a plot with a $\log ($ area) axis, such as in Figure 5, coverage is easily visualized from the difference between $\log$ (field) and $\log$ (domain). The M-cell receptive-field curve RF and the M-dom curve are close to parallel, so coverage is close to being constant, as is shown explicitly in Figure 10.

Coverage calculations have also been based on anatomical measurements of dendritic-field size (cf. Fig. 5). Perry et al. (1984) found a coverage factor of 2-7 for $P_{\alpha}$ cells, independent of eccentricity. Using the receptive-field size of $\mathrm{M}$ cells [equation (8)], the coverage factor we compute for $M$ cells increases about 4 -fold from a value of 3.8 at $1^{\circ}$ eccentricity, in good agreement with their result. The 2 -fold difference, consistent with receptive-field diameters just 1.4-fold larger than dendritic-field diameters (cf. Fig. 5), is not unexpected because of the less-thanexact correspondence between receptive-field and dendritic-field areas in cat retina (Cleland and Levick, 1974; Peichl and Wassle, $1979,1981)$ and macaque retina (Perry et al., 1984).

In the cat retina, studies of receptive-field coverage (Peichl and Wassle, 1979) show a nearly constant coverage for $Y$ cells (3-6) but a steep increase in the coverage of $X$ cells, from 7-10 in the periphery to $30 \mathrm{in}$. in the area centralis. In this respect, the $M$ cells resemble cat $Y$ cells.

\section{Specific eccentricity dependences}

When plotted in consistent units of visual-field area $\left(\mathrm{deg}^{2}\right)$, the various quantities described in this paper seem to fall naturally into 2 families of eccentricity dependence. One family is shown in Figure $11 A$, including (1) the reciprocal of the density of $\mathrm{P}$ cells in the retina $\left(\mathrm{deg}^{2} / \mathrm{cell}\right)$, an area that could be geometrically visualized as the visual-field domain of a P cell; (2) the reciprocal of the density of V1 modules ( $\mathrm{deg}^{2} /$ module), which could be visualized as the visual-field domain of a cortical module; and (3) the reciprocal of the ACMF $\left(\mathrm{deg}^{2} / \mathrm{mm}^{2}\right)$. The other family is shown in Fig. $11 B$, including (1) the reciprocal of the density of $\mathrm{M}$ cells, or the M-cell domain ( $\left.\mathrm{deg}^{2} / \mathrm{cell}\right)$ and (2) the area of the V1 point image $\left(\mathrm{deg}^{2}\right)$.

Figure $11 C$ shows these same data, but with the curves vertically displaced to equal 1 at $1^{\circ}$ eccentricity. After this normalization, the curves of Figure $11 \mathrm{~A}$ constitute the upper family of solid curves, whereas the curves of Figure $11 B$ constitute the lower family. We regard these as the P- and M-cell families, respectively. In addition, the isolated, dotted curve of Figure $11 C$ shows the normalized curve of areas of receptive-field centers of $M$ cells. Such a curve for P-cell receptive fields would be flatter than the lowest family of curves (de Monasterio and Gouras, 1975), especially in the central $10^{\circ}$ (see also Perry et al., 1984, and Rodieck et al., 1985). The receptive-field curves follow neither family of eccentricity dependencies.

The eccentricity dependencies of the 2 families are graphically shown in Figure 12. In the bottom row, the large, dark squares show the increase with eccentricity of the visual-field domain $\left(\mathrm{deg}^{2}\right)$ of $110 \mathrm{P}$ cells in 1 eye. The larger, circular areas show that of $70 \mathrm{M}$ cells. Rescaling the figures (top row) emphasizes how the P-cell domain increases more steeply with eccentricity than the M-cell domain.

In Figure 13 the dark squares show the nearly constant cortical domain (in $\mathrm{mm}^{2}$ ) in V1 of 2 eyes' worth of the same sets of 110 $P$ cells as were shown in Figure 12. This area corresponds to the cortical domain of 2 cytochrome oxidase puffs. The larger, open circles, the cortical domain (in $\mathrm{mm}^{2}$ ) in V1 of 2 eyes' worth of $70 \mathrm{M}$ cells, correspond to the area of a V1 point image, which declines with eccentricity.

Can the biological parameters analyzed in this paper underlie specific psychophysical measures of visual performance? These 

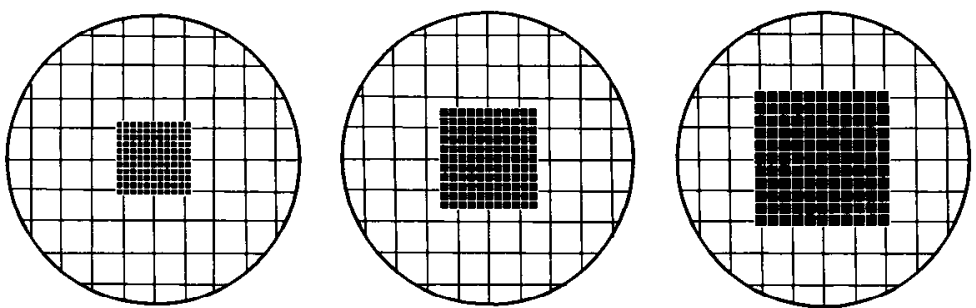

$10^{\circ}$

$2^{\circ}$

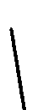

1
$1 \quad \ldots$
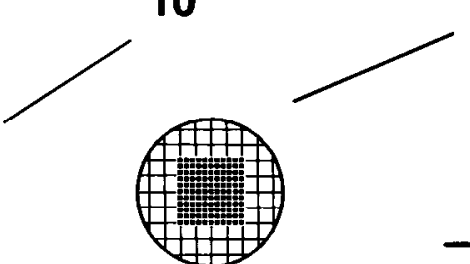

$30^{\circ}$
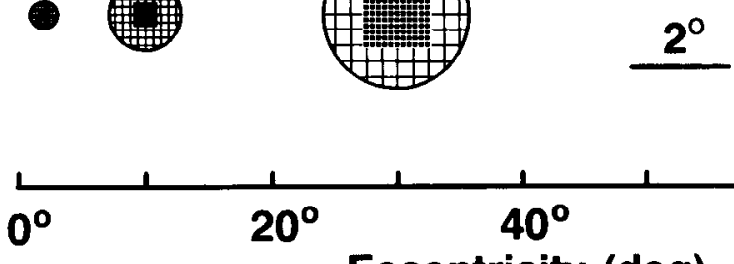

Visual field domain

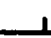

$60^{\circ}$

$40^{\circ}$

deg) $\left(\mathrm{deg}^{2}\right)$ of $110 \mathrm{P}$ cells

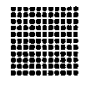

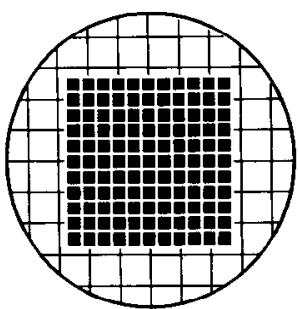

$80^{\circ}$

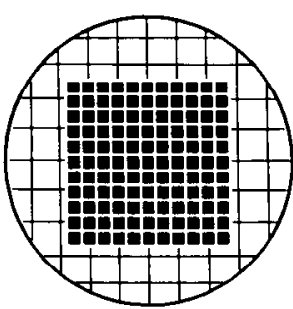

$80^{\circ}$

\section{Visual field domain}

$\left(\operatorname{deg}^{2}\right)$ of $70 \mathrm{M}$ cells
Figure 12. Bottom, Representation of the visual-field domain of $110 \mathrm{P}$ cells (large squares) and $70 \mathrm{M}$ cells (large circles). Note that the $2^{\circ}$ calibration scale for the size of the circles and squares is different from the eccentricity scale. The large squares are each filled with 110 individual P-cell domains, the large circles with $70 \mathrm{M}$ cell domains. Top, Representation of the change in relative domain size of $P$ cells, as compared to $M$ cells. Items from the bottom row were expanded in size so that the representation of $M$-cell domains would be equal in the top row. parameters, shown in Figure 11, include P-cell density and receptive-field size, $\mathrm{M}$-cell density and receptive-field size, cortical magnification, and module density. Our analysis provides 2 quantitative criteria necessary for such a selective assignment, viz., the shape of the eccentricity dependence and the absolute magnitudes of the quantities. On the basis of these criteria, we suggest elsewhere (Schein and de Monasterio, 1986) selective assignments for hyperacuity, perceptive fields, the critical area for luminance summation (Ricco's area), and spatial contrast sensitivity.

\section{References}

Albus, K. (1975) A quantitative study of the projection area of the central and the paracentral visual field in area 17 of the cat. I. The precision of the topography. Exp. Brain Res. 24: 159-179.

Bishop, P. O., W. Kozak, W. R. Levick, and G. J. Vakkur (1962) The determination of the projection of the visual field onto the lateral geniculate nucleus in the cat. J. Physiol. (Lond.) 163: 503-539.

Blasdel, G. G., and D. Fitzpatrick (1984) Physiological organization of layer 4 in macaque striate cortex. J. Neurosci. 4: 880-895.

Blasdel, G. G., and J. S. Lund (1983) Terminations of afferent axons in macaque striate cortex. J. Neurosci. 3: 1389-1413.
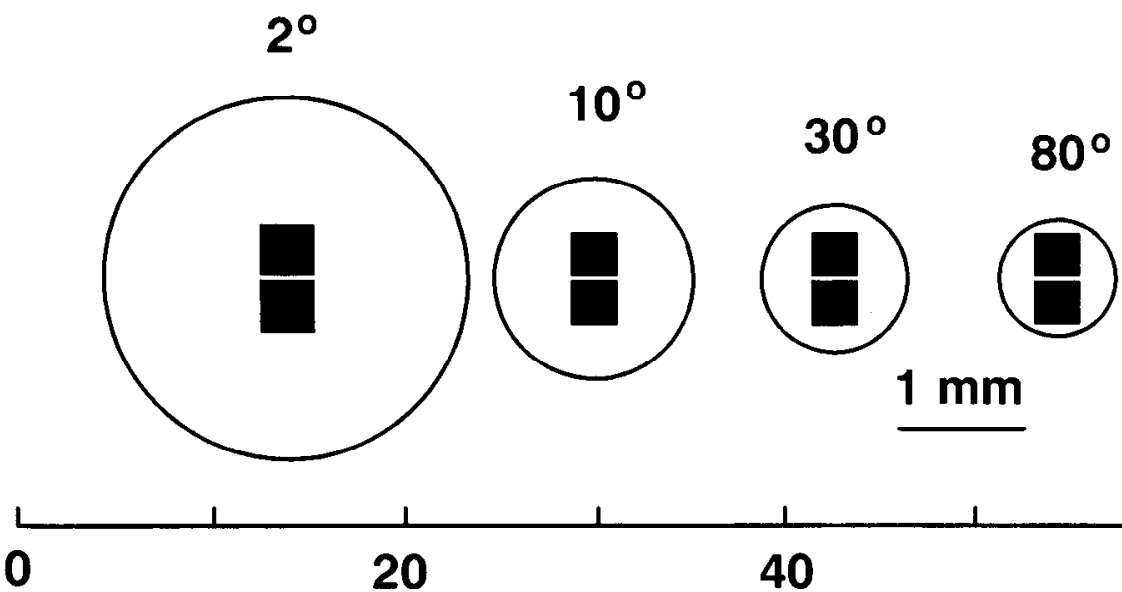

20

1

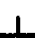

40

60

Distance in V1 $(\mathrm{mm})$

\section{V1 domain $\left(\mathrm{mm}^{2}\right)$ of $110 \mathrm{P}$ cells}

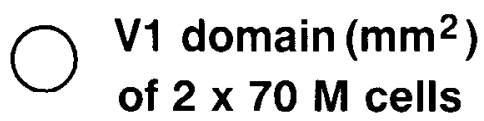

Figure 13. The cortical domain of 2 eyes' worth of $110 \mathrm{P}$ cells (filled squares) and 2 eyes' worth of $70 \mathrm{M}$ cells (open circles). The $1 \mathrm{~mm}$ calibration scale for the size of circles and squares is different from the eccentricity scale, a logarithmic scale based on equation (6). The visual-field domain of $110 \mathrm{P}$ cells from each eye corresponds to the domain of a cytochrome oxidase puff in $\mathrm{V} 1 ; 2$ eyes' worth corresponds to 2 puff domains. The domain of $140 \mathrm{M}$ cells, 70 from each eye, corresponds to the area of a Vl cortical point image. 
Blasdel, G. G., and G. Salama (1986) Voltage-sensitive dyes reveal a modular organization in monkey striate cortex. Nature 321:579-585.

Bruesch, S. L., and L. B. Arey (1942) The number of myelinated and unmyelinated fibres in the optic nerve of vertebrates. J. Comp. Neurol. 77: 631-665.

Bunt, A. H., A. E. Hendrickson, V. S. Lund, R. D. Lund, and A. F. Fuchs (1975) Monkey retinal ganglion cells: Morphometric analysis and tracing of axonal projections, with a consideration of peroxidase technique. J. Comp. Neurol. 164:265-286.

Campbell, F. W., and R. W. Gubisch (1966) Optical quality of the human eye. J. Physiol. (Lond.) 186: 558-578.

Chacko, L. W. (1948) The laminar pattern of the lateral geniculate body in the primates. J. Neurol. Neurosurg. Psychiatry 11:211-224.

Chow, K. L., J. S. Blum, and R. A. Blum (1950) Cell ratios in the thalamo-cortical visual system of Macaca mulatta. J. Comp. Neurol. 92: 227-239.

Clark, W. E. L. (1941) The laminar organization and cell content of the lateral geniculate body in the monkey. J. Anat. 74: 419-433.

Cleland, B. G., and W. R. Levick (1974) Brisk and sluggish concentrically organized ganglion cells in the cat's retina. J. Physiol. (Lond.) 240: 421-456.

Cleland, B. G., W. R. Levick, and H. Wassle (1975) Physiological identification of a morphological class of cat retinal ganglion cells. J. Physiol. (Lond.) 248: 151-171.

Connolly, M., and D. C. Van Essen (1984) The representation of the visual field in parvicellular and magnocellular laminae of the lateral geniculate nucleus in the macaque monkey. J. Comp. Neurol. 226: 544-564.

Daniel, P. M., and D. Whitteridge (1961) The representation of the visual field on the cerebral cortex in monkeys. J. Physiol. (Lond.) 159: 203-221.

de Monasterio, F. M. (1978a) Properties of concentrically-organized $\mathrm{X}$ and $\mathrm{Y}$ ganglion cells of the retina of macaques. J. Neurophysiol. 41: 1394-1417.

de Monasterio, F. M. (1978b) Center and surround mechanisms of opponent-colour $\mathrm{X}$ and $\mathrm{Y}$ ganglion cells of the retina of macaques. J. Neurophysiol. 41: 1418-1434.

de Monasterio, F. M. (1978c) Properties of ganglion cells with atypical receptive-field organization in retina of macaques. J. Neurophysiol. 41: 1435-1449.

de Monasterio, F. M. (1979) Asymmetry of on- and off-pathways of blue-sensitive cones of the retina of macaques. Brain Res. 19: 441449.

de Monasterio, F. M., and P. Gouras (1975) Functional properties of ganglion cells of the rhesus monkey retina. J. Physiol. (Lond.) 251: 167-196.

de Monasterio, F. M., P. Gouras, and D. J. Tolhurst (1975) Concealed colour opponency in ganglion cells of the rhesus monkey retina. J. Physiol. (Lond.) 251: 217-229.

de Monasterio, F. M., S. J. Schein, and E. P. McCrane (1981) Staining of blue-sensitive cones of the macaque retina by a fluorescent dye. Science 213: 1278-1281.

de Monasterio, F. M., E. P. McCrane, J. K. Newlander, and S. J. Schein (1985) Density profile of blue-sensitive cones along the horizontal meridian of macaque retina. Invest. Ophthalmol. Vis. Sci. 26: 289302.

Derrington, A. M., and P. Lennie (1984) Spatial and temporal contrast sensitivities of neurones in lateral geniculate nucleus of macaque. J. Physiol. (Lond.) 357: 219-240.

Derrington, A. M., J. Krauskopf, and P. Lennie (1984) Chromatic mechanisms in lateral geniculate nucleus of macaque. J. Physiol. (Lond.) 357: 241-265.

Dow, B. M., R. G. Snyder, R. G. Vautin, and R. Bauer (1981) Magnification factor and receptive field size in foveal striate cortex of the monkey. Exp. Brain Res. 44: 213-228.

Dow, B. M., R. G. Vautin, and R. Bauer (1985) The mapping of visual space onto foveal striate cortex in the macaque monkey. J. Neurosci. 5: $890-902$.

Drasdo, N. (1977) The neural representation of visual space. Nature 266: 554-556.

Drasdo, N., and C. W. Fowler (1974) Non-linear projection of the retinal image in a wide-angle schematic eye. $\mathrm{Br}$. J. Ophthalmol. 58: 709-714.

Dreher, B., Y. Fukuda, and R. W. Rodieck (1976) Identification, classification and anatomical segregation of cells with $X$-like and $Y$-like properties in the lateral geniculate nucleus of old-world primates. J. Physiol. (Lond.) 258: 433-452.

Fischer, B. (1973) Overlap of receptive field centers and representation of the visual in the cat's optic tract. Vision Res. 13: 2113-2120.

Gouras, P. (1969) Antidromic responses of orthodromically identified ganglion cells in monkey retina. J. Physiol. (Lond.) 205: 407-419.

Hendrickson, A. E., J. R. Wilson, and M. P. Ogren (1978) The neuroanatomical organization of pathways between the dorsal lateral geniculate nucleus and visual cortex in Old World and New World primates. J. Comp. Neurol. 182: 123-136.

Hendrickson, A. E., S. P. Hunt, and J. Y. Wu (1981) Immunocytochemical localization of glutamic acid decarboxylase in monkey striate cortex. Nature 292: 605-607.

Horton, J. C. (1984) Cytochrome oxidase patches: A new cytoarchitectonic feature of monkey visual cortex. Phil. Trans. R. Soc. Lond. [Biol.] 304: 199-253.

Horton, J. C., and D. H. Hubel (1980) Cytochrome oxidase stain preferentially labels intersection of ocular dominance and vertical orientation column in macaque striate cortex. Soc. Neurosci. Abstr. 6: 315 .

Horton, J. C., and D. H. Hubel (1981) Regular patchy distribution of cytochrome oxidase staining in primary visual cortex of macaque monkey. Nature 292: 762-764.

Hubel, D. H., and T. N. Wiesel (1972) Laminar and columnar distribution of geniculo-cortical fibers in the macaque monkey. J. Comp. Neurol. 146: 421-450.

Hubel, D. H., and D. C. Freeman (1977) Projection into the visual field of ocular dominance columns in macaque monkey. Brain Res. 122: 336-343.

Hubel, D. H., and T. N. Wiesel (1974) Uniformity of monkey striate cortex: A parallel relationship between field size, scatter, and magnification factor. J. Comp. Neurol. 158: 295-306.

Hubel, D. H., and T. N. Wiesel (1977) Ferrier Lecture: Functional architecture of macaque monkey visual cortex. Proc. R. Soc. Lond. [Biol.] 198: 1-59.

Humphrey, A. L., and A. E. Hendrickson (1980) Radial zones of high metabolic activity in squirrel monkey striate cortex. Soc. Neurosci. Abstr. 6: 315 .

Humphrey, A. L., and A. E. Hendrickson (1983) Background and stimulus induced patterns of high metabolic activity in the visual cortex (area 17) of the squirrel and macaque monkey. J. Neurosci. 3. 345-358.

Kaplan, E., and R. M. Shapley (1982) X and Y cells in the lateral geniculate nucleus of macaque monkeys. J. Physiol. (Lond.) 330: 12513.

Killackey, H. P., and M. Snyder (1973) Differential retrograde cell response of the dorsal and ventral layers of the monkey dorsal lateral geniculate body following lesions of the striate cortex. Anat. Rec. 175: 358 .

Kupfer, C., L. Chumbley, and J. De C. Downer (1967) Quantitative histology of optic nerve, optic tract and lateral geniculate nucleus of man. J. Anat. 101: 393-401.

LeVay, S., M. Connolly, J. Houde, and D. C. Van Essen (1985) The complete pattern of ocular dominance stripes in the striate cortex and visual field of the macaque monkey. J. Neurosci. 5: 486-501.

Leventhal, A. G., R. W. Rodieck, and B. Dreher (1981) Retinal ganglion cell classes in old-world monkey: Morphology and central projections. Science 213: 1139-1142.

Levi, D. M., S. A. Klein, and A. P. Aitsebaomo (1985) Vernier acuity, crowding and cortical magnification. Vision Res. 25: 963-977.

Livingstone, M. S., and D. H. Hubel (1984) Anatomy and physiology of a color system in the primate visual cortex. J. Neurosci. 4: 309356

Lund, J. S. (1973) Organization of neurons in the visual cortex, area 17, of the monkey (Macaca mulatta). J. Comp. Neurol. 147: 455496.

Malpeli, J. G., and F. H. Baker (1975) The representation of the visual field in the lateral geniculate nucleus of Macaca mulatta. J. Comp. Neurol. 161: 569-594.

Malpeli, J. G., and P. H. Schiller (1978) Lack of blue off-center cells in the visual system of the monkey. Brain Res. 141: 385-389.

Mariani, A. P., F. M. de Monasterio, and E. P. McCrane (1985) Alpha, beta and midget ganglion cells of macaque retina. Invest. Ophthalmol. Vis. Sci. (Suppl.) 26: 262.

Marrocco, R. T. (1976) Sustained and transient cells in monkey lateral 
geniculate nucleus: Conduction velocities and response properties. I. Neurophysiol. 39: 340-353.

Marrocco, R. T., J. W. McClurkin, and R. A. Young (1982) Spatial summation and conduction latency classification of cells of the lateral geniculate nucleus of macaques. J. Neurosci. 2: 1275-1291.

McCrane, E. P., S. J. Schein, and F. M. de Monasterio (1982) Pattern of cytochrome oxidase in striate cortex of normal and monocular macaques. Invest. Ophthalmol. Vis. Sci. (Suppl.) 22: 244.

McIlwain, J. T. (1975) Visual receptive fields and their images in superior colliculus of the cat. J. Neurophysiol. 38: 219-230.

Mcllwain, J. T. (1976) Large receptive fields and spatial transformations in the visual system. Int. Rev. Physiol. 10: 223-248.

Missotten, L. (1974) Estimation of the ratio of cones to neurons in the fovea of the human retina. Invest. Ophthalmol. Vis. Sci. 13: 10451049.

Myerson, J., P. B. Manis, R. M. Miezin, and J. M. Allman (1977) Magnification in striate cortex and the retinal ganglion cell layer of the owl monkey: A quantitative comparison. Science 198: 855-857.

Ogden, T. E., and R. F. Miller (1966) Studies of the optic nerve of the rhesus monkey: Nerve fiber spectrum and physiological properties. Vision Res. 6: 485-506.

Peichl, L., and H. Wassle (1979) Size, scatter and coverage of ganglion cell receptive field centres in the cat retina. J. Physiol. (Lond.) 291: 117-141.

Peichl, L., and H. Wassle (1981) The structural correlate of the receptive field centre of ganglion cells in the cat retina. J. Physiol. (Lond.) 341: 309-324.

Perry, V. H., and A. Cowey (1984) Retinal ganglion cells that project to the superior colliculus and pretectum in the macaque monkey. Neuroscience 12: 1125-1137.

Perry, V. H., and A. Cowey (1985) The ganglion cell and cone distributions in the monkey's retina: Implications for central magnification factors. Vision Res. 12: 1795-1810.

Perry, V. H., R. Oehler, and A. Cowey (1984) Retinal ganglion cells that project to the dorsal lateral geniculate nucleus in the macaque monkey. Neuroscience 12: 1101-1123.

Polyak, S. L. (1941) The Retina, U. Chicago P., Chicago.

Polyak, S. L. (1957) The Vertebrate Visual System, U. Chicago P., Chicago.

Potts, A. M., D. Hodges, C. B. Shelman, K. J. Fritz, N. S. Levey, and Y. Mangnall (1972) Morphology of the primate optic nerve: I. Method and total fiber count. Invest. Ophthalmol. 11: 980-998.

Rakic, P., and K. P. Riley (1983) Overproduction and elimination of retinal axons in the fetal rhesus monkey. Science 219: 1441-1444.

Rodieck, R. W., K. F. Binmoeller, and J. Dineen (1985) Parasol and midget ganglion cells of human retina. J. Comp. Neurol. 233: 115132.

Rolls, E. T., and A. Cowey (1970) Topography of the retina and striate cortex and its relationship to visual acuity in rhesus monkeys and squirrel monkeys. Exp. Brain Res. 10: 298-310.

Rovamo, J., and V. Virsu (1979) An estimation and application of the human cortical magnification factor. Exp. Brain Res. 37: 475494.

Rovamo, J., and V. Virsu (1984) Isotropy of cortical magnification and topography of striate cortex. Vision Res. 24: 283-286.

Sakitt, B., and H. B. Barlow (1982) A model for the economical encoding of the visual image in cerebral cortex. Biol. Cybern. 43: 97108.

Sanderson, K. J. (1971) Visual field projection columns and magnification factors in the lateral geniculate nucleus of the cat. Exp. Brain Res. 13: 159-177.

Schein, S. J., and F. M. de Monasterio (1985) The mapping of retinalgeniculatc ncurons onto macaque V1. Invest. Ophthalmol. Vis. Sci. (Suppl.) 26: 165 .
Schein, S. J., and F. M. de Monasterio (1986) Psychophysical correlates of separate retinal and V1 magnifications. Invest. Ophthalmol. Vis. Sci. (Suppl.) 27: 94.

Schiller, P. H., and C. L. Colby (1983) The responses of single cells in the lateral geniculate nucleus of the rhesus monkey to color and luminance contrast. Vision Res. 23: 1631-1641.

Schiller, P. H., and J. G. Malpeli (1977) Properties and tectal projections of monkey retinal ganglion cells. J. Neurophysiol. 40: 428-445.

Schwartz, E. L. (1977) Spatial mapping in the primate sensory projection: Analytic structure and relevance to perception. Biol. Cybern. 25: 181-194.

Schwartz, E. L. (1980) Computational anatomy and functional architecture of striate cortex: A spatial mapping approach to perceptual coding. Vision Res. 20: 645-670.

Schwartz, E. (1983) Cortical mapping and perceptual invariance: A reply to Cavanagh. Vision Res. 23: 831-835.

Shapiro, M., S. J. Schein, and F. M. de Monasterio (1985) Regularity and structure of the spatial pattcrn of bluc cones of macaque retina. J. Am. Stat. Assoc. 80: 803-814.

Shapley, R. M., E. Kaplan, and R. Soodak (1981) Spatial summation and contrast sensitivity of $\mathrm{X}$ and $\mathrm{Y}$ cells in the lateral geniculate nucleus of the macaque. Nature 292: 543-545.

Talbot, S. A., and W. H. Marshall (1941) Physiological studies on neural mechanisms of visual localization and discrimination. Am. J. Ophthalmol. 24: 1255-1264.

Tootell, R., M. Silverman, E. Switkes and R. DeValois (1982) Deoxyglucose analysis of retinotopic organization of primate striate cortex. Science 218: 902-904.

Tusa, R. J., L. A. Palmer, and A. C. Rosenquist (1978) The retinotopic organization of area 17 (striate cortex) in the cat. J. Comp. Neurol. 177: 213-236.

Van Buren, J. M. (1963) The Retinal Ganglion Cell Layer, Thomas, Springfield, IL.

Van Essen, D. C., W. T. Newsome, and J. H. R. Maunsell (1984) The visual field representation in striate cortex of the macaque monkey: Asymmetries, anisotropies, and individual variability. Vision Res. 24: 429-448.

Von Noorden, G. K., and P. R. Middleditch (1975) Histological observations in the normal monkey lateral geniculate nucleus. Invest. Ophthalmol. 14: 55-58.

Wald, G. (1967) Blue-blindness in the normal fovea. J. Opt. Soc. Am. 57: 1289-1301.

Wassle, H., I. Peichl, and B. B. Boycott (1981a) Morphology and topography of on- and off-alpha cells in the cat retina. Proc. R. Soc. Lond. [Biol.] 212: 157-175.

Wassle, H., B. B. Boycott, and R. B. Illing (1981b) Morphology and mosaic of on- and off-beta cells in the cat retina and some functional considerations. Proc. R. Soc. Lond. [Biol.] 212: 177-195.

Webb, S. V., and J. H. Kaas (1976) The sizes and distribution of ganglion cells in the retina of the owl monkey, Aotus trivirgatus. Vision Res. 16: 1247-1254.

Wiesel, 'T. N., and D. H. Hubel (1966) Spatial and chromatic interactions in the lateral geniculate body of the rhesus monkey. J. Neurophysiol. 29: 1115-1156.

Williams, D. R., D. I. A. MacLeod, and M. M. Hayhoe (1981) Foveal tritanopia. Vision Res. 21: 1341-1356.

Wilson, J. R., and S. M. Sherman (1976) Receptive-field characteristics of neurons in cat striate cortex: Changes with visual field eccentricity. J. Neurophysiol. 39: 512-533.

Woolsey, C. N., W. H. Marshall, and P. Bard (1942) Representation of cutaneous tactile sensibility in the cerebral cortex of the monkey as indicated by evoked potentials. Bull. Johns Hopkins Hosp. 70: 399-441. 